\title{
A comparison among four different retrieval methods for ice-cloud properties using data from CloudSat, CALIPSO, and MODIS
}

Article

Published Version

Stein, T. H. M., Delanoë, J. and Hogan, R. J. (2011) A comparison among four different retrieval methods for icecloud properties using data from CloudSat, CALIPSO, and MODIS. Journal of Applied Meteorology and Climatology, 50 (9). pp. 1952-1969. ISSN 1558-8432 doi: https://doi.org/10.1175/2011JAMC2646.1 Available at https://centaur.reading.ac.uk/24143/

It is advisable to refer to the publisher's version if you intend to cite from the work. See Guidance on citing.

To link to this article DOI: http://dx.doi.org/10.1175/2011JAMC2646.1

Publisher: American Meteorological Society

All outputs in CentAUR are protected by Intellectual Property Rights law, including copyright law. Copyright and IPR is retained by the creators or other copyright holders. Terms and conditions for use of this material are defined in the End User Agreement. 


\section{www.reading.ac.uk/centaur}

\section{CentAUR}

Central Archive at the University of Reading

Reading's research outputs online 


\title{
A Comparison among Four Different Retrieval Methods for Ice-Cloud Properties Using Data from CloudSat, CALIPSO, and MODIS
}

\author{
THORWALD H. M. STEIN \\ Department of Meteorology, University of Reading, Reading, United Kingdom \\ JULIEN DELANOË \\ Department of Meteorology, University of Reading, United Kingdom, and LATMOS/IPSL/UVSQ/CNRS, Guyancourt, France \\ ROBIN J. HOGAN \\ Department of Meteorology, University of Reading, Reading, United Kingdom
}

(Manuscript received 2 September 2010, in final form 26 February 2011)

\begin{abstract}
The A-Train constellation of satellites provides a new capability to measure vertical cloud profiles that leads to more detailed information on ice-cloud microphysical properties than has been possible up to now. A variational radar-lidar ice-cloud retrieval algorithm (VarCloud) takes advantage of the complementary nature of the CloudSat radar and Cloud-Aerosol Lidar and Infrared Pathfinder Satellite Observations (CALIPSO) lidar to provide a seamless retrieval of ice water content, effective radius, and extinction coefficient from the thinnest cirrus (seen only by the lidar) to the thickest ice cloud (penetrated only by the radar). In this paper, several versions of the VarCloud retrieval are compared with the CloudSat standard iceonly retrieval of ice water content, two empirical formulas that derive ice water content from radar reflectivity and temperature, and retrievals of vertically integrated properties from the Moderate Resolution Imaging Spectroradiometer (MODIS) radiometer. The retrieved variables typically agree to within a factor of 2, on average, and most of the differences can be explained by the different microphysical assumptions. For example, the ice water content comparison illustrates the sensitivity of the retrievals to assumed ice particle shape. If ice particles are modeled as oblate spheroids rather than spheres for radar scattering then the retrieved ice water content is reduced by on average $50 \%$ in clouds with a reflectivity factor larger than $0 \mathrm{dBZ}$. VarCloud retrieves optical depths that are on average a factor-of-2 lower than those from MODIS, which can be explained by the different assumptions on particle mass and area; if VarCloud mimics the MODIS assumptions then better agreement is found in effective radius and optical depth is overestimated. MODIS predicts the mean vertically integrated ice water content to be around a factor-of- 3 lower than that from VarCloud for the same retrievals, however, because the MODIS algorithm assumes that its retrieved effective radius (which is mostly representative of cloud top) is constant throughout the depth of the cloud. These comparisons highlight the need to refine microphysical assumptions in all retrieval algorithms and also for future studies to compare not only the mean values but also the full probability density function.
\end{abstract}

\section{Introduction}

The advent of satellite observations has provided access to cloud data from across the globe, and their statistics allow for the creation of cloud "climatologies" (Warren and Hahn 2002). These global cloud observations are vital

\footnotetext{
Corresponding author address: Thorwald Stein, Dept. of Meteorology, University of Reading, Earley Gate, P.O. Box 243, Reading, RG6 6BB, United Kingdom.

E-mail: t.h.m.stein@reading.ac.uk
}

to set constraints on general circulation models (GCMs), which show differences in ice water path (IWP) of a factor of 10 or more, but the current satellite cloud-ice retrievals often disagree because of varying footprints and instrument and algorithm sensitivities (Waliser et al. 2009). The A-Train constellation of satellites takes various measurements of ice clouds (Stephens et al. 2002). It started with the launch of Aqua in 2002, carrying the Moderate Resolution Imaging Spectroradiometer (MODIS), which retrieves cloud optical properties using shortwave and infrared radiances. In 2006, Aqua was joined by CloudSat 
and the Cloud-Aerosol Lidar and Infrared Pathfinder Satellite Observations (CALIPSO) (Winker et al. 2003), providing vertical profiles of clouds around the globe on a daily basis. These near-coincident measurements are ideal for combined retrieval techniques and to compare single-instrument cloud-ice retrievals.

The synergy of coincident radar and lidar observations is well documented (Intrieri et al. 1993; Donovan et al. 2001; Okamoto et al. 2003; Mitrescu et al. 2005; Tinel et al. 2005; Hogan et al. 2006a) and is already used to determine accurately the occurrence of hydrometeor layers by the CloudSat cloud profiling radar (CPR) and the CALIPSO lidar (Mace et al. 2009). Delanoë and Hogan (2008) developed an optimal estimation algorithm to retrieve cloud-ice properties from ground-based radar and lidar observations and recently adapted it to CloudSat and CALIPSO (Delanoë and Hogan 2010). A combined radar-lidar algorithm can retrieve ice particle size and concentration independently, and better estimates of these variables should be obtained than if a single instrument were used (Hogan et al. 2006a).

In this paper, the coincident A-Train measurements are used to study algorithm and instrument sensitivities for ice-cloud retrievals. The following methods are compared:

1) the combined radar-lidar optimal estimation retrieval developed by Delanoë and Hogan (2010), hereinafter referred to as VarCloud,

2) the radar-only, ice-only version of the standard CloudSat product (Austin et al. 2009),

3) two empirical formulas for ice water content (IWC) as a function of radar reflectivity factor $Z$ and temperature $T[\operatorname{IWC}(Z, T)]$ (Hogan et al. 2006b; Protat et al. 2007), and

4) the MODIS level-2 cloud product (King et al. 1997).

The first three of these products retrieve IWC using at least two of the same inputs-namely, the equivalent radar reflectivity factor $Z_{e}$ observed by the CPR and temperature $T$ along the CloudSat track provided by the European Centre for Medium-Range Weather Forecasts (ECMWF). A direct comparison of IWC retrievals is possible where the radar is sensitive to ice cloud, so that the dependence of deviations in IWC on either temperature or reflectivity can be analyzed.

Cloud-ice retrievals strongly depend on the representation of ice particles in terms of their shape, size, and distribution (McFarquhar and Heymsfield 1998; Heymsfield et al. 2008). With the introduction of the different products in section 2, we will also provide an overview of the ice particle assumptions made in each retrieval.

The results are presented fourfold, starting with section 3 in which the global distribution of ice clouds with temperature will be discussed. A cloud classification using CloudSat and CALIPSO data is used to compare ice-cloud occurrence as observed by the radar and lidar individually and jointly. The different IWC retrievals are compared in section 4 through the joint probability distribution of IWC versus temperature. Where differences among retrievals occur, the impact of instrument and algorithm sensitivities is discussed, including the effect of different ice particle assumptions. In section 5, this comparison focuses on individual IWC retrievals and the mean fractional differences of IWC among the various methods.

Vertically integrated ice-cloud retrievals are presented in section 6. Because MODIS is not designed to provide vertical profiles, we compare it with the VarCloud product using the in-cloud zonal averages of IWP. The MODIS IWP is inferred from the retrieval of optical depth $\tau$ and mean effective radius $\left\langle r_{e}\right\rangle$ (King et al. 2006), which are retrieved by VarCloud and provide an additional comparison with MODIS.

\section{Method}

Here, we introduce the four different retrieval methods that will be used for comparison in this paper. For a quick overview of the satellite products, Fig. 1 shows vertical profiles and the optical depth of a single cloud observed by the A-Train in the South Atlantic Ocean. The ice particle assumptions for the variables of interest in this paper are discussed below for each product and are summarized in Table 1.

\section{a. VarCloud}

A variational retrieval algorithm using ground-based lidar and radar data was introduced by Delanoë and Hogan (2008). This method has recently been adapted to accommodate the measurements from the CPR and CALIPSO lidar (Delanoë and Hogan 2010) and in the present paper is referred to as VarCloud.

In this retrieval, the lidar and radar data are first merged onto the same grid. The CPR provides a vertical profile of $Z_{e}$ at approximately $1.5-\mathrm{km}$ horizontal resolution and $240-\mathrm{m}$ vertical resolution. The CALIPSO lidar provides attenuated backscatter coefficient $\beta$ at $333-\mathrm{m}$ horizontal resolution and at a variable vertical resolution of 30-60 $\mathrm{m}$ in the troposphere. CloudSat reflectivities are linearly interpolated from their 240-m vertical resolution onto a regular 60-m grid, and the lidar signal is averaged horizontally onto the CloudSat $1.5-\mathrm{km}$ horizontal grid before being averaged up to the regular 60 -m vertical grid. A similar interpolation is performed on the ECMWF temperature, pressure, and humidity variables, which are from the short-range forecasts under 
(a) Lidar attenuated backscatter $\left[\log _{10} \mathrm{~m}^{-1} \mathrm{sr}^{-1}\right]$

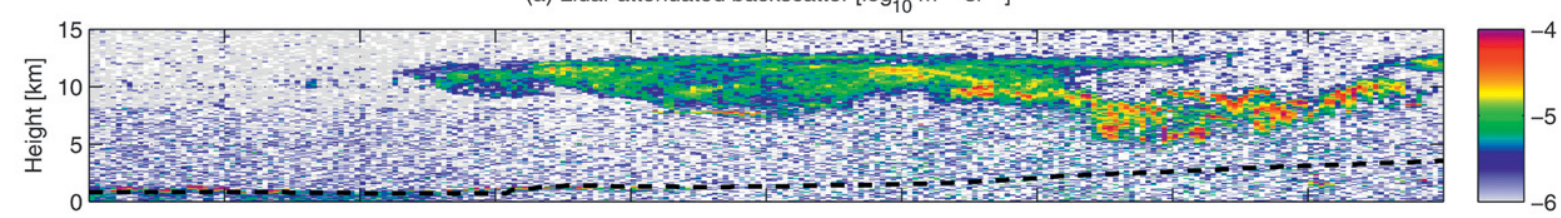

(b) Radar reflectivity factor [dBZ]

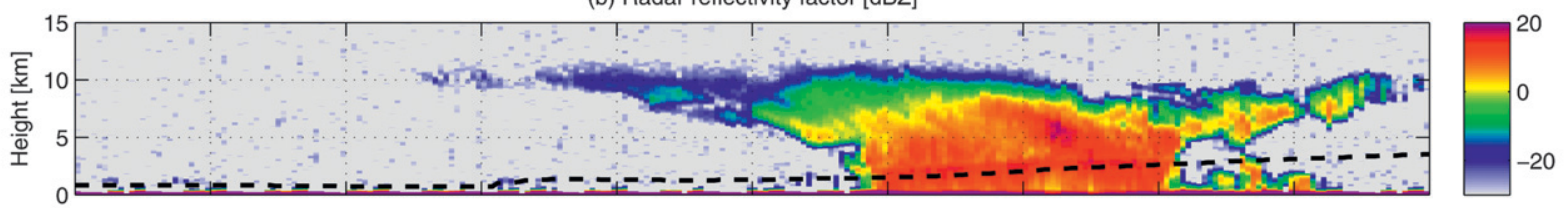

(c) VarCloud-OA IWC $\left[\log _{10} \mathrm{~kg} \mathrm{~m}^{-3}\right]$

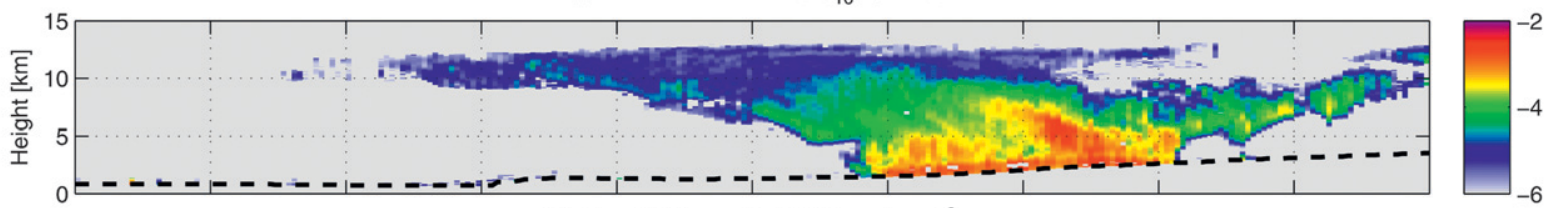

(d) CloudSat ice-only IWC $\left[\log _{10} \mathrm{~kg} \mathrm{~m}^{-3}\right]$

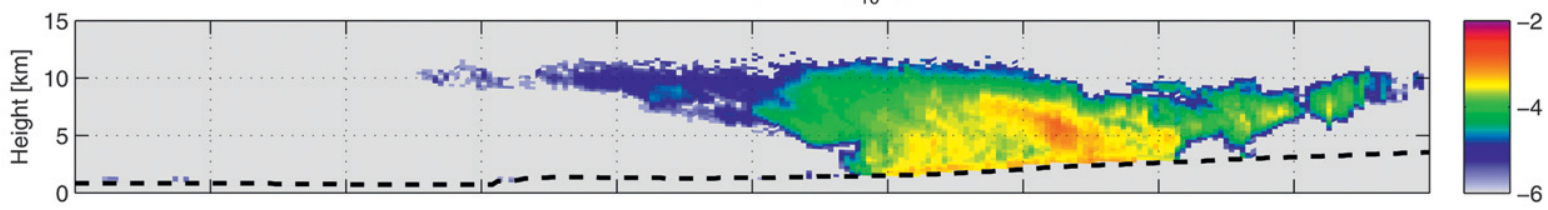

(e) Optical depth

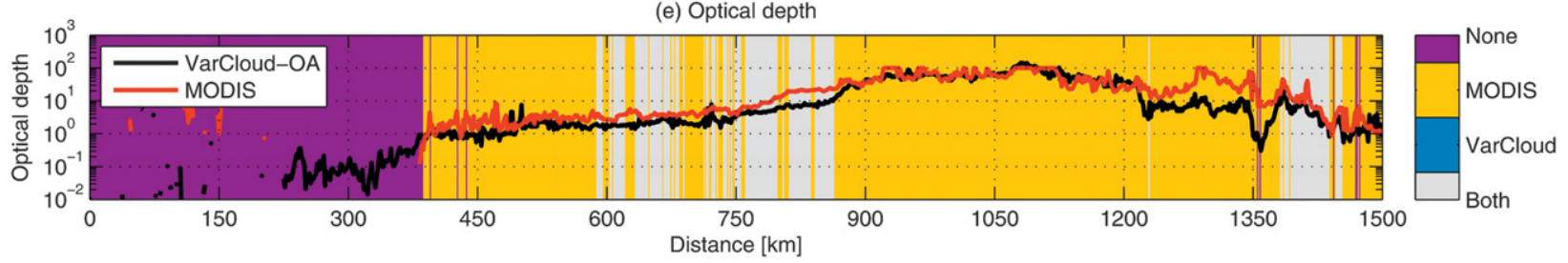

FIG. 1. CloudSat observations from orbit 01126 and collocated MODIS and CALIPSO data, 1636:23-1639:04 UTC 14 Jul 2006. (a) Attenuated backscatter coefficient observed by the lidar. (b) Radar reflectivity factor $Z_{e}$ observed by the CPR. (c) IWC retrieved by VarCloud-OA. (d) IWC from the CloudSat ice-only product. (e) Optical depth retrieved by VarCloud-OA (black) and MODIS (red), with colored shading indicating which product has determined the profile to contain only ice. In (a)-(d), the dashed line shows the height of $T_{w}=0^{\circ} \mathrm{C}$ from the ECMWF modeled temperatures.

the CloudSat track, so that the necessary inputs for the VarCloud algorithm are available on a regular $1.5-\mathrm{km}$ grid with 60-m vertical resolution.

On this merged grid, the VarCloud target classification is performed (Delanoë and Hogan 2010) taking as input the CloudSat cloud mask in the "2B-GEOPROF" (geometrical profile) product (Mace 2004) and the "lidar level 2 vertical feature mask" (Anselmo et al. 2007). This classification scheme identifies a target as cloud when the lidar mask has identified cloud or when the radar mask reports a value of 30 or greater, which indicates a high confidence in cloud detection. Once a cloud has been determined, it is set to be ice phase when $T_{w}<0^{\circ} \mathrm{C}$, with the occurrence of supercooled liquid identified by a strong lidar backscatter signal. This cloud classification is used in section 3 in combination with the instrument flag (radar, lidar, or both) to determine icecloud occurrence.

The VarCloud method uses an optimal estimation formulation, in which an initial estimate of the cloud variables in a single vertical profile (the state vector) is used in a forward model to predict the radar reflectivity factor and apparent lidar backscatter in that profile (the observation vector). At each vertical level, the state vector contains an estimate of the visible extinction coefficient $\alpha_{v}$ in the geometric optics approximation, the lidar extinction-to-backscatter ratio $S$, and the "normalized" number concentration $N_{0}^{*}$. The particle size distribution is obtained assuming a normalized modified gamma distribution, multiplied by $N_{0}^{*}$ (Delanoë et al. 2005). The forward model then calculates at each vertical level the radar reflectivity factor $Z_{e}$ using a lookup 
TABLE 1. A summary of the products used for comparison and their ice particle assumptions for calculating scattering properties. Products with "aggregates" make use of the Brown and Francis (1995) mass-diameter relationship and Francis et al. (1998) area-size relationship. "Habit mixture" stands for size-dependent distributions of plates, hollow columns, bullet rosettes, and aggregates as formulated by Baum et al. (2005a,b). "Bullet rosettes" employ the Mitchell (1996) mass-area-size relationship. "Equivalent volume" assumes the equivalent spherical volume for the ice crystal (Stephens et al. 1990). The radar scattering model is most relevant to retrievals with high $Z_{e}$ and relates to the shape assumption for large particles in the non-Rayleigh scattering regime. For the CloudSat product, "parameterized Mie" uses Mie theory with a correction factor and is derived from Benedetti et al. (2003). The "modified" gamma distribution used in the VarCloud retrievals has coefficients $(-1,3)$ and is "normalized" as described in Delanoë et al. (2005).

\begin{tabular}{llll}
\hline \multicolumn{1}{c}{ Product } & \multicolumn{1}{c}{ Radar scattering model } & $\begin{array}{c}\text { Mass-area-size } \\
\text { relationship }\end{array}$ & $\begin{array}{c}\text { Particle size } \\
\text { distribution }\end{array}$ \\
\hline VarCloud-OA (Delanoë and Hogan 2010) & Oblate spheroids (T matrix) & Aggregates & Modified gamma \\
VarCloud-SA & Spheres (Mie scattering) & Aggregates & Modified gamma \\
VarCloud-BR & Spheres (Mie scattering) & Bullet rosettes & Modified gamma \\
Formula IWC $(Z, T)$ (Hogan et al. 2006b; & Spheres (Mie scattering) & Aggregates & Aircraft distributions \\
$\quad$ Protat et al. 2007) & Spheres (parameterized Mie) & Equivalent volume & Lognormal \\
CloudSat IWC (Austin et al. 2009) & - & Habit mixture & Gamma distribution \\
MODIS IWP (King et al. 2006) & & &
\end{tabular}

table derived from rigorous scattering calculations, and the apparent lidar backscatter coefficient $\beta$ using a multiple-scattering model (Hogan 2006). Note that the Hogan (2006) model is much more accurate than simply scaling the optical depth by a constant in the lidar equation currently used in the Cloud-Aerosol Lidar with Orthogonal Polarization (CALIOP) retrievals (Winker 2003; Winker et al. 2009), as illustrated in Hogan (2008). The difference between the forward-modeled observations and the actual observed variables is used to refine the state vector using the Gauss-Newton method (Rodgers 2000). This process is repeated until convergence following a $\chi^{2}$ test. The retrieval can be further constrained if additional measurements are available for forward modeling, for instance infrared radiances or cloud visible optical depth retrieved during the day by shortwave radiances, although this capability is not used in this paper.

The VarCloud algorithm contains a rigorous treatment of errors in which errors are attributed to assumptions in the forward model, to the error covariances of the a priori estimates (number concentration and $S$ ), as well as the observations. Note that errors in the lidar forward model due to the use of the Hogan (2006) multiplescattering model are smaller than the errors due to unrepresented variations of $S$ in the profile. The inclusion of the a priori estimates allows for the retrieval to proceed when only a single instrument is available. In the absence of lidar observations the retrieval tends to behave similarly to a relationship for IWC as a function of $Z_{e}$ and $T$, and in the absence of radar observations the a priori estimates ensure that the retrieval behaves similarly to a constrained lidar-only retrieval, making use of the molecular return below the cloud as an optical depth constraint, when available. This results in a seamless retrieval between optically thin ice clouds only seen by lidar and deep ice clouds only seen by radar, through cloud seen by both instruments.

To investigate the dependence of the retrievals on microphysical assumptions, three versions of the VarCloud retrieval method are used. The standard VarCloud product (Delanoë and Hogan 2010) will be referred to as VarCloud-OA (for "oblate aggregates") and uses the T-matrix method to perform scattering calculations assuming that ice particles can be approximated by horizontally aligned oblate spheroids with an axial ratio of 0.6 (Hogan et al. 2011, manuscript submitted to J. Appl. Meteor. Climatol.). The VarCloud-SA (for "spherical aggregates") assumes spherical shapes for radar scattering calculations using Mie theory. Both VarCloud-OA and VarCloud-SA use the Brown and Francis (1995) mass-diameter relationship for the ice particle model and in their scattering calculations. This relationship was found by Hogan et al. (2006b) to provide a very accurate estimate of radar reflectivity. The VarCloud-BR (for "bullet rosette") version is only introduced as a potentially better match with the MODIS ice particle assumptions, for which bullet rosettes dominate the ice particle mixtures (King et al. 1997; Platnick et al. 2003; Baum et al. 2005a,b). In VarCloud$\mathrm{BR}$, Mie theory is applied to perform radar scattering calculations while the ice particle model uses the Mitchell (1996) mass-area-size relationship for bullet rosettes.

\section{b. Standard CloudSat radar-only product}

The "level 2B radar-only cloud water content" product (2B-CWC-RO) is provided by the National Aeronautics and Space Administration (NASA) CloudSat project (Austin et al. 2009). This product makes use of optimal estimation theory, in which a lognormal size distribution $N(D)$ of ice particles is assumed, 


$$
N(D)=\frac{N_{T}}{\sqrt{2 \pi} \omega D} \exp \left[\frac{-\ln ^{2}\left(D / D_{g}\right)}{2 \omega^{2}}\right],
$$

with the particle number concentration $N_{T}$, the width of the distribution $\omega$, and the geometric mean diameter $D_{g}$ being the retrieved state variables at each radar range gate, all three with temperature-dependent a priori assumptions. The forward model then simulates values of the radar reflectivity factor $Z_{e}$ for comparison with the observations using the three size distribution parameters. First, Eq. (1) is used to calculate Rayleigh reflectivity, after which Mie theory is applied in the form of a correction factor parameterized using the size distribution parameters $\omega$ and $D_{g}$ (Benedetti et al. 2003) to obtain $Z_{e}$.

This optimal estimation algorithm provides IWC for two different CloudSat radar-only products. In the standard CloudSat product (2B-CWC-RO), separate ice and liquid retrievals are scaled linearly with temperature between $0^{\circ}$ and $-20^{\circ} \mathrm{C}$ by adjusting the respective particle number concentrations, resulting in a profile with ice-only retrievals at temperatures below $-20^{\circ} \mathrm{C}$ and a smooth transition to liquid-only retrievals at temperatures above $0^{\circ} \mathrm{C}$. A second version (with subscript IO, for "ice only") assumes that the radar reflectivity is dominated by the contribution from ice particles and does not attempt to estimate liquid water content below $0^{\circ} \mathrm{C}$. This is consistent with assumptions in VarCloud and should provide a better comparison between the two products. It is also supported by observational evidence that $Z_{e}$ is dominated by ice in mixed-phase clouds (Hogan et al. 2003; Zuidema et al. 2005). Therefore, the ice-only CloudSat product rather than the standard version is used in this paper to compare IWC retrievals and will be referred to as "CloudSat ice-only."

\section{c. Empirical formula for IWC as a function of reflectivity and temperature}

For empirical formulas relating IWC to $Z_{e}$ using aircraft measurements, the size distribution is provided by the measurements and no assumptions on its shape need to be made. Hogan et al. (2006b) derived the following empirical relationship for the expected value of IWC as a function of $94-\mathrm{GHz}$ radar reflectivity factor $Z$ and temperature $T$ :

$$
\begin{aligned}
\log _{10}(\mathrm{IWC})= & 0.000580 Z T+0.0923 Z \\
& -0.00706 T-0.992
\end{aligned}
$$

which will be referred to as H06. Here, IWC is given in grams per meter cubed, radar reflectivity factor $Z$ is in reflectivity decibels (dBZ), and $T$ is in degrees Celsius.
Equation (2) was derived from size spectra measured in frontal ice clouds around the United Kingdom. The Brown and Francis (1995) mass-diameter relationship was applied to obtain IWC and $Z$, and Mie theory was applied for radar scattering, which assumes that particles are modeled as spheres consisting of a homogeneous mixture of ice and air. The CloudSat products assume a different calibration for the $94-\mathrm{GHz}$ radar than the empirical formulas $\operatorname{IWC}(Z, T)$. A conversion from the CloudSat observed $Z_{e}$ to the $Z$ in Eq. (2) is done by

$$
Z_{e}=\frac{0.93}{\left|K_{w}\left(T_{0}\right)\right|^{2}} Z
$$

where 0.93 is the dielectric factor of liquid water at centimeter wavelengths used in the empirical formulas $\operatorname{IWC}(Z, T)$ (Hogan et al. 2006b; Protat et al. 2007) and $\left|K_{w}\left(T_{0}\right)\right|^{2}=0.75$ is the value used to calibrate the CPR, which is the dielectric factor of liquid water at $10^{\circ} \mathrm{C}$ at $94 \mathrm{GHz}$ (Tanelli et al. 2008). Formulas such as Eq. (2) provide a best fit for $\operatorname{IWC}(Z, T)$ given the observations from which they are derived, which is a different approach from the VarCloud and CloudSat retrievals, even though the latter uses exactly the same inputs: $Z_{e}$ and $T$. The fractional error for IWC derived using Eq. (2) is $+55 \% /-35 \%$ between $-20^{\circ}$ and $-10^{\circ} \mathrm{C}$ and $+90 \% /$ $-47 \%$ for $T<-40^{\circ} \mathrm{C}$ (Hogan et al. 2006b).

The inputs for the empirical Eq. (2) are the temperatures from ECMWF and the equivalent radar reflectivity factor $Z_{e}$ from the CloudSat product 2B-GEOPROF, converted using Eq. (3). In this estimation of IWC the 2-way gas attenuation down to $0^{\circ} \mathrm{C}$ will be ignored, for this is typically less than $0.5 \mathrm{~dB}$ (Hogan and Illingworth 1999).

The formula $\operatorname{IWC}(Z, T)$ in Eq. (2) was derived using an aircraft measurement dataset for Northern Hemisphere midlatitudes only. Protat et al. (2007) evaluated this formula against data that included tropical cirrus and found that IWC estimates from Eq. (2) had fractional errors of $+80 \%$ and $-44 \%$ relative to the IWC calculated from the true size distribution. The $\operatorname{IWC}(Z, T)$ relationship derived by Protat et al. (2007) for the global dataset produced fractional errors of $+69 \% /-41 \%$. Because the a priori estimates for VarCloud are derived from the same dataset used by Protat et al. (2007), we will include their empirical formula in our comparison of the mean root-mean-square (rms) difference between the different products. This relationship is

$$
\begin{aligned}
\log _{10}(\mathrm{IWC})= & 0.000491 Z T+0.0939 Z \\
& -0.0023 T-0.84,
\end{aligned}
$$

which will be referred to as P07. Similar to H06, this formula is derived using Mie theory for radar scattering 
in the non-Rayleigh regime. The Brown and Francis (1995) mass-diameter relationship is also applied, but using $D_{\max }$ as the diameter rather than $D_{\text {mean }}$, which leads to an overestimate in IWC of about $50 \%$ (Hogan et al. 2011, manuscript submitted to J. Appl. Meteor. Climatol.).

\section{d. Standard MODIS product}

MODIS measures reflectances at 36 wavelengths, including visible and near-infrared bands. For each cloudy pixel the MODIS retrieval determines the thermodynamic phase (ice, liquid, mixed, or uncertain), with the remainder of pixels flagged as "clear" (King et al. 2004).

Ice-cloud optical depth $\tau$ and mean effective radius $\left\langle r_{e}\right\rangle$ in the MODIS products are derived through the best fit of the reflectance for a given observation to library calculations assuming plane-parallel homogeneous clouds (King et al. 1997). The ice reflectance library is generated from a database of 1117 ice particle size distributions from different field campaigns in the midlatitudes and in the tropics (Baum et al. 2005a,b). The reflectance functions are calculated at the MODIS visible and near-infrared wavelength bands for each size distribution and a range of optical thicknesses $\tau$, providing a lookup table for comparison with measured reflectance. Through a $\chi^{2}$ test of the calculated reflectance and the measured reflectances, the combination of the size distribution and the optical thickness providing the best fit for all wavelength bands is retrieved.

The retrieval of $\left\langle r_{e}\right\rangle$ through the use of radiometer observations is heavily weighted to the cloud top (McFarquhar and Heymsfield 1998; Platnick 2000). For instance, McFarquhar and Heymsfield (1998) used a radiative transfer code to show that in the near-infrared 2.2- $\mu \mathrm{m}$ channel, only the uppermost four or five optical depths of the cloud contribute to the reflectance. Therefore, $\left\langle r_{e}\right\rangle$ retrievals for optically thick ice clouds will be dominated by particles near cloud top. In the retrieval of $\tau$ and $\left\langle r_{e}\right\rangle, r_{e}$ and IWC are assumed to be constant with height, so that IWP is derived from optical thickness and $\left\langle r_{e}\right\rangle$ (King et al. 2006) using

$$
\mathrm{IWP}=\frac{4}{3} \frac{\rho_{\text {ice }} \tau\left\langle r_{e}\right\rangle}{Q_{\mathrm{ext}}\left(r_{e} / \lambda\right)},
$$

with the extinction efficiency $Q_{\text {ext }}\left(r_{e} / \lambda\right)$ assumed to be equal to 2 at the reference wavelength for $\tau(\lambda=0.66 \mu \mathrm{m})$.

\section{Ice-cloud occurrence}

Prior to a comparison of the different products by their retrieval of IWC, the radar and lidar are compared by the fraction of ice clouds that they observe. The VarCloud target classification contains a flag indicating whether the observation was made by radar, lidar, or both. This way, the cloud occurrence measured by the radar and lidar combined can easily be determined, as well as the fraction of that portion observed by a single instrument. This will give us a first estimate on the fraction of ice clouds missed by a single instrument (see also Stephens et al. 2008).

We restrict ourselves to tropospheric ice clouds, that is, ice cloud observed at temperatures below $0^{\circ} \mathrm{C}$ and located below the tropopause height, which is provided in the CALIPSO dataset and determined by NASA's Global Modeling and Assimilation Office as the first minimum above the surface of the function $0.03 T$ $\log _{10} p$, with pressure $p$ between 550 and $40 \mathrm{hPa}$. This range will be referred to as the subzero troposphere. The ice-cloud occurrences presented should therefore be interpreted in relation to this subzero troposphere.

The data are gathered into bins of $2^{\circ}$ latitude, indicated by $\phi_{k}$, with the extreme latitudes of a typical A-Train orbit at $81.8^{\circ}$ north and south; occurrences that depend on temperature are binned per degree Celsius, indicated by $T_{j}$; and $j$ and $k$ are indices to the bins. The following probabilities are then calculated for each latitude within the subzero troposphere:

1) $\mathcal{P}_{k}\left(C \wedge T_{j}\right)$ : probability of ice-cloud occurrence and temperature $T_{j}$ at latitude $\phi_{k}$,

2) $\mathcal{P}_{k}\left(T_{j}\right)$ : probability of temperature $T_{j}$ at latitude $\phi_{k}$, and

3) $\mathcal{P}_{k}\left(C \mid T_{j}\right)$ : probability of ice-cloud occurrence given temperature $T_{j}$ and at latitude $\phi_{k}$,

where " $\wedge$ " denotes a joint occurrence, "|" signifies a conditional probability, and $C$ is an ice-cloud observation as classified in VarCloud.

Using Bayes's theorem, the ice-cloud occurrence for a given temperature is obtained from the observations as follows:

$$
\mathcal{P}_{k}\left(C \mid T_{j}\right)=\frac{\mathcal{N}_{k}\left(C \wedge T_{j}\right)}{\mathcal{N}_{k}\left(T_{j}\right)},
$$

where $\mathcal{N}$ indicates the number of individual observations of the given temperature and/or cloud scene. These occurrences, shown in Figs. 2a-d, reveal a vertical structure of the zonal average that is similar to that which has been presented in previous studies that make use of CloudSat and/or CALIPSO data (Bodas-Salcedo et al. 2008; Mace et al. 2009; Wu et al. 2009). The distinction among radar-only, lidar-only, and radar-lidar observations, however, highlights the advantages of the combined product. The radar does not detect many of the optically thinner ice clouds at lower temperatures (usually higher altitudes) for which the lidar shows higher 

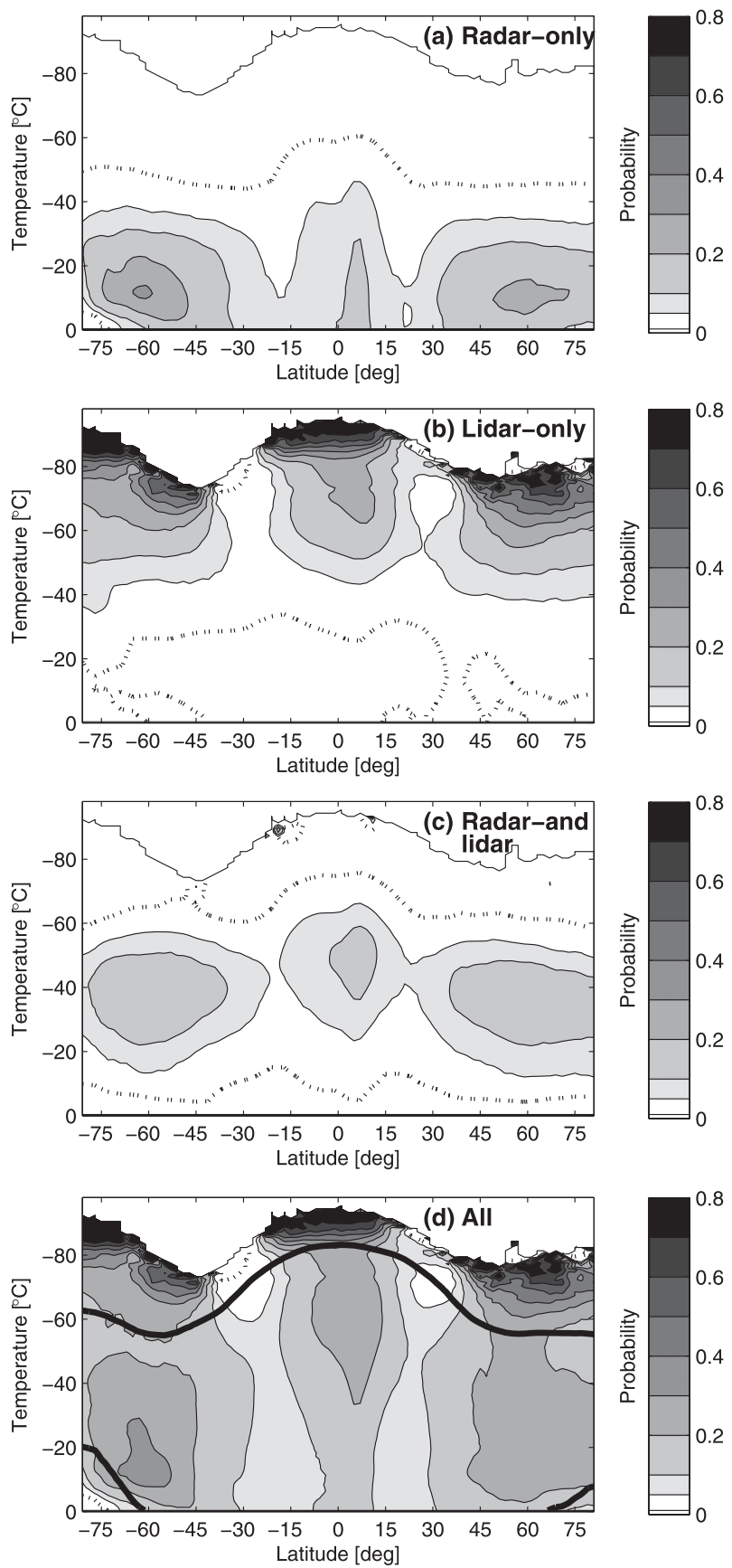

FIG. 2. Probability of observing ice cloud in the subzero troposphere for a given temperature $T_{j}$ and latitude $k$ [i.e., $\mathcal{P}_{k}\left(C \mid T_{j}\right)$ ] for (a) radar only, (b) lidar only, (c) radar and lidar together, and (d) either radar or lidar or both. Dashed lines show the 0.01 probability contour. Thick lines in (d) indicate the $90 \mathrm{~m}^{\circ} \mathrm{C}^{-1}$ contour for temperature occurrence derived using Eq. (7), thereby indicating where the sample is small and the results may be less reliable. Data are from 2008.

ice-cloud occurrence. On the other hand, the lidar signal is often extinguished before it reaches the melting layer and observes less than 5\% ice-cloud occurrence per degree Celsius for most temperatures warmer than $-10^{\circ} \mathrm{C}$ where the radar regularly observes more than $10 \%$ occurrence. The ice-cloud occurrence observed by both radar and lidar (Fig. 2d) shows some of the cloud climatological features that can be expected in a year. The intertropical convergence zone can be seen to vary near the equator between $5^{\circ} \mathrm{S}$ and $10^{\circ} \mathrm{N}$, higher icecloud occurrences highlight the storm tracks of the northern and southern midlatitudes and the descending branches of the Hadley cell result in lower ice-cloud occurrences between $15^{\circ}$ and $30^{\circ}$ on either side of the equator.

The very high ice-cloud occurrences at the coldest temperatures in Fig. $2 \mathrm{~d}$ are deceptive, which is indicated using the temperature layer depth — that is, the variation of height with temperature, given by

$$
L_{k}\left(T_{j}\right)=\frac{\mathcal{N}_{k}\left(T_{j}\right)}{\mathcal{V}_{k}} \Delta z
$$

with $\mathcal{V}_{k}$ being the total number of vertical profiles at latitude $\phi_{k}$ and $\Delta z$ being the VarCloud vertical resolution of $60 \mathrm{~m}$. Thus, $L_{k}\left(T_{j}\right)$ has the dimensions of meters per degree Celsius, or the inverse of a lapse rate, and low values of $L_{k}\left(T_{j}\right)$ occur at the cold temperatures near the tropopause, where the lapse rate increases. When these cold temperatures do occur in the subzero troposphere, they tend to be associated with cloud as indicated by the relatively high occurrences. In the Antarctic, this combination of low temperature layer depth and high cloud occurrence could be due to poor determination of the polar tropopause (Zängl and Hoinka 2001) and subsequent inclusion of polar stratospheric clouds, whereas in the tropics it may be linked to overshooting convection.

In Fig. 3, the probabilities $\mathcal{P}_{k}\left(C \wedge T_{j}\right)$ and $\mathcal{P}_{k}\left(C \mid T_{j}\right)$ [given by Eq. (6)] are averaged over the latitude bins to obtain the global ice-cloud occurrence. For each bin $k$ the probability is weighted by the area $A_{k}$ of a sphere between the appropriate latitudes, thus giving a larger weight to cloud occurrences in the tropics than at midlatitudes. To obtain a measure of volume, $A_{k}$ is multiplied by the mean depth of the subzero troposphere per profile at latitude $\phi_{k}$, given by

$$
\left\langle L_{k}\right\rangle=\sum_{j} L_{k}\left(T_{j}\right)
$$

In addition, probabilities conditional on temperature $T_{j}$ such as Eq. (6) are weighted by the temperature occurrence at that latitude given by $\mathcal{P}_{k}\left(T_{j}\right)$. The globally averaged probability of the ice-cloud occurrence conditional on the occurrence of $T_{j}$ is then calculated from Eq. (6) as 

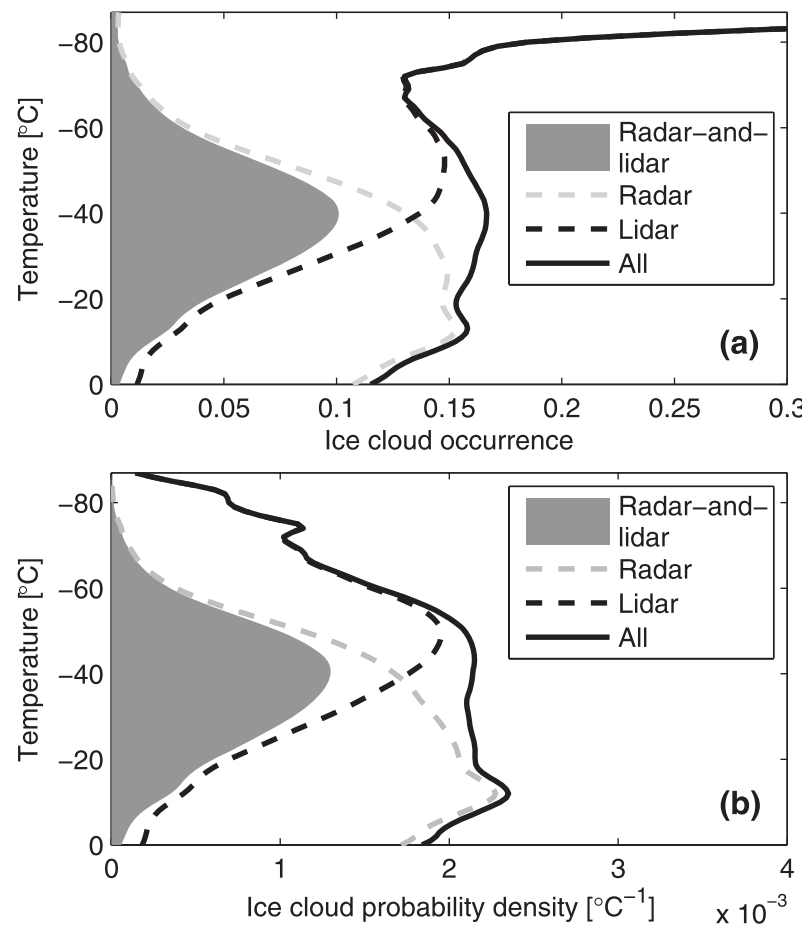

FIG. 3. (a) Global ice-cloud occurrence vs temperature $T_{j}$ [i.e., $\mathcal{P}\left(C \mid T_{j}\right)$ ] for different instrument combinations. These graphs can be interpreted as the average of ice-cloud occurrence in Figs. 2a-d weighted by latitude. (b) Global distribution of ice clouds and temperature $T_{j}$ between the melting layer and the tropopause [i.e., $\left.\mathcal{P}\left(C \wedge T_{j}\right)\right]$. This can be interpreted as a weighted average of Figs. 2a-d, multiplied by $\mathcal{P}\left(T_{j}\right)$. Data are from 2008 .

$$
\mathcal{P}\left(C \mid T_{j}\right)=\frac{\sum_{k} A_{k}\left\langle L_{k}\right\rangle \mathcal{P}_{k}\left(T_{j}\right) \mathcal{P}_{k}\left(C \mid T_{j}\right)}{\sum_{k} A_{k}\left\langle L_{k}\right\rangle \mathcal{P}_{k}\left(T_{j}\right)},
$$

where the combined weight of area, mean number, and temperature occurrence appears in the denominator and the subscript $k$ is dropped on the left-hand side to denote the global probability.

In Fig. 3, combinations of observations from different instruments indicate the global cloud occurrence observed by

1) "radar," which includes "radar only" and "radar and lidar" observations,

2) "lidar," which includes "lidar only" and "radar and lidar" observations, and

3) "all," which includes "radar only," "lidar only," and "radar and lidar" observations.

The globally averaged conditional ice-cloud occurrences in Fig. 3a peak at temperatures colder than $-70^{\circ} \mathrm{C}$ when they include all lidar observations, similar to Figs. 2c,d. If one assumes that the ice-cloud occurrence observed from all radar and lidar observations is the total ice-cloud occurrence, in Fig. 3a the fraction of ice clouds observed coincidentally by both instruments reaches over $50 \%$ at temperatures between $-30.0^{\circ}$ and $-48.0^{\circ} \mathrm{C}$, providing a large range of temperatures over which a combined radarlidar ice-cloud retrieval is applicable. The radar detects at least $50 \%$ of the ice clouds observed by the combination of the two instruments at temperatures that are warmer than $-51.0^{\circ} \mathrm{C}$, whereas the lidar detects over $50 \%$ at temperatures that are colder than $-27.0^{\circ} \mathrm{C}$.

The global averages for the joint ice-cloud and temperature occurrence $\mathcal{P}\left(C \wedge T_{j}\right)$ are shown in Fig. $3 \mathrm{~b}$. Integrating $\mathcal{P}\left(C \wedge T_{j}\right)$ over temperature, we obtain the fraction of the volume of the subzero troposphere filled with ice cloud, which for 2008 gives $15.3 \%$ for all radar and lidar observations. Using only observations for which at least the radar is available, this reduces to $10.5 \%$, whereas for the lidar it is $9.6 \%$. If we assume the combined product to give the "true" ice-cloud occurrence, we can conclude that radar and lidar observe $68.4 \%$ and $62.6 \%$ of tropospheric ice cloud, respectively, for 2008 , with $31.0 \%$ observed by both the radar and the lidar. For 2007, we found that the global ice-cloud volume fraction was $15.4 \%$ for all radar and lidar observations, $10.4 \%$ for radar observations, and $10.0 \%$ for lidar observations. The slight decrease in ice cloud observed by the lidar in 2008 is found when comparing individual months as well and can be attributed to specular reflection from oriented crystals, which was strongly reduced by the change in lidar orientation from $0.3^{\circ}$ to $3.0^{\circ}$ off nadir on 27 November 2007 (Hu et al. 2007; Noel and Chepfer 2010).

\section{Ice water content distribution versus temperature}

The deviation between different IWC retrievals from radar or radar-and-lidar observations is studied in this section using the joint probability density distribution of IWC versus temperature. Figure 4 displays the all-sky joint distribution of IWC versus temperature for CloudSat ice-only, $\operatorname{H06} \operatorname{IWC}(Z, T)$, and the VarCloud-OA retrievals. Probabilities are calculated for each latitude, temperature, and IWC bin as follows:

$$
\mathcal{P}_{k}\left(\mathrm{IWC}_{x} \wedge T_{j}\right)=\frac{\mathcal{N}_{k}\left(\mathrm{IWC}_{x} \wedge T_{j}\right)}{\mathcal{N}_{k}},
$$

with $x$ denoting logarithmic bins for IWC. These probabilities are subsequently weighted by $A_{k}$ and $\left\langle L_{k}\right\rangle$ to obtain the globally averaged joint distributions of IWC versus $T$. The contour plots in Fig. 4 highlight several differences among the various products. First of all, the empirical formula of $\mathrm{H} 06$ given by Eq. (2) may be directly compared with the CloudSat ice-only retrieval because both products use only radar reflectivity and temperature 

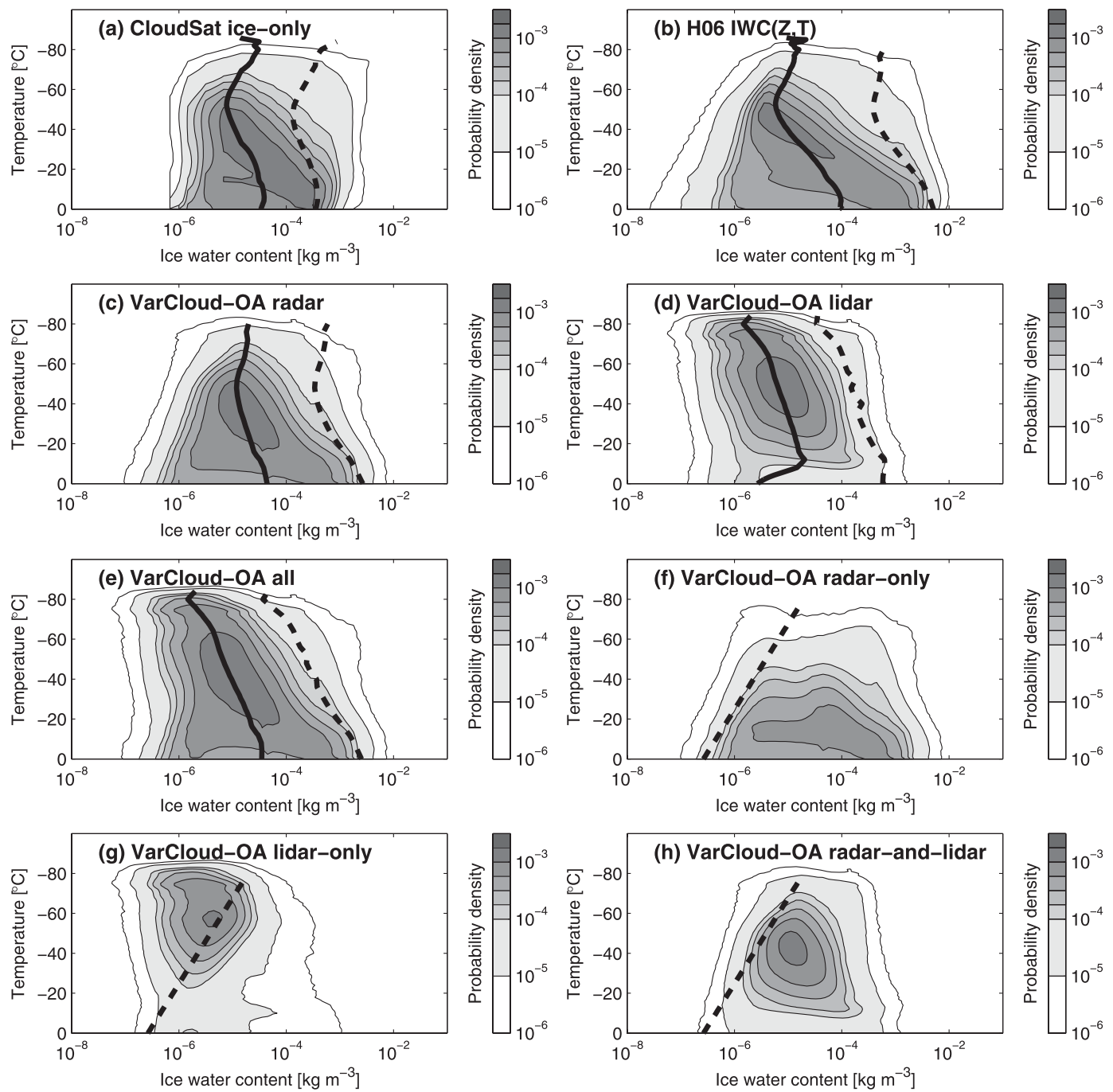

FIG. 4. IWC vs $T$ frequency distribution for all skies [i.e., $\left.\mathcal{P}\left(\operatorname{IWC}_{x} \wedge T_{j}\right)\right]$. Values are weighted averages over orbits and latitudes and are represented as the probability density per degree Celsius per $\log _{10}\left(\mathrm{~kg} \mathrm{~m}^{-3}\right)$. (a)-(e) The in-cloud median (solid) and weighted mean (dashed) IWC at each temperature are also shown. (f)-(h) The dashed line indicates the IWC retrieved by $\mathrm{H} 06$ at the CloudSat sensitivity threshold of $-28 \mathrm{dBZ}$. Data are from October 2008.

to obtain IWC. At temperatures that are colder than $-20^{\circ} \mathrm{C}$ the two products show a similar distribution of IWC, disregarding the tail at lower IWC values beyond the CloudSat ice-only minimum IWC of $10^{-6} \mathrm{~kg} \mathrm{~m}^{-3}$.

The complete VarCloud-OA IWC retrieval is shown in Fig. 4e, the distribution including all radar observations is shown in Fig. 4c, and the distribution including all lidar observations is shown in Fig. 4d. The inclusion of lidar observations extends the IWC distribution to higher occurrences at lower IWC values and colder temperatures relative to the radar-only retrievals in Figs. 4a-c. Figures 4f-h show the IWC from VarCloudOA where ice clouds are observed by radar-only (Fig. 4f), lidar-only (Fig. 4g), and radar and lidar (Fig. 4h). In these panels, the H06 retrieval at the CloudSat sensitivity threshold of $-28 \mathrm{dBZ}$ roughly separates the lidar-only IWC retrievals from the retrievals that include radar observations (dashed line).

In Figs. 4a-e we also show the in-cloud median and mean IWC versus temperature, that is, the median and mean IWC for a given temperature only including values of IWC $>0$. The domination of the in-cloud mean by the highest IWC values is apparent from Fig. 5 , which shows the cumulative in-cloud IWC distribution versus temperature. For all retrievals and at all temperatures, the in-cloud mean IWC lies between the 95th and 99th percentile. For a given temperature, the contours in Figs. 4a-e are approximately evenly spread on either side of the median, so that the IWC distribution at a given temperature is comparable to a 

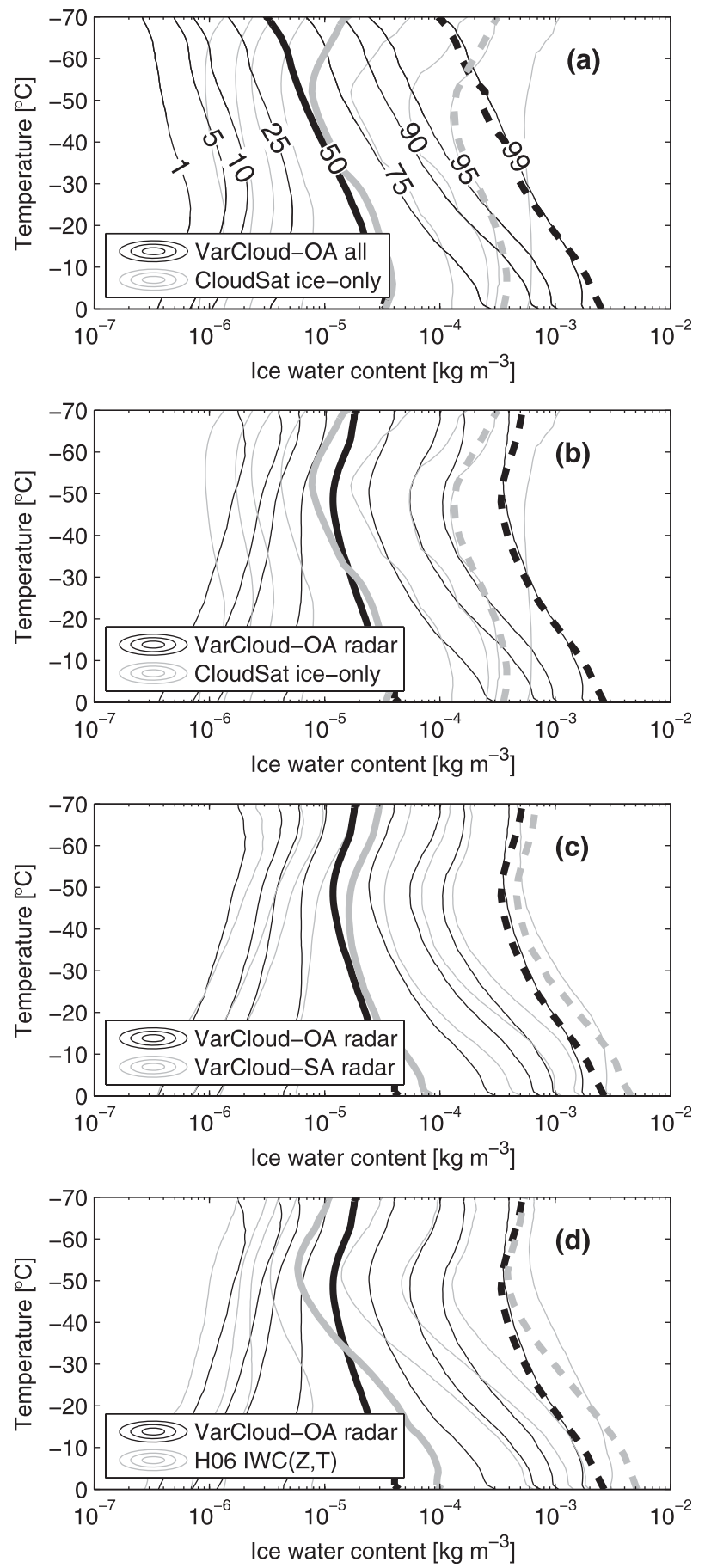

FIG. 5. In-cloud cumulative distribution of IWC vs $T$. From left to right, thin contours show the cumulative percentiles at $1 \%, 5 \%$, $10 \%, 25 \%, 75 \%, 90 \%, 95 \%$, and $99 \%$. Thick solid lines are the medians $(50 \%)$, and dashed lines are the means as shown in Figs. 4a-e. (a) VarCloud-OA all (black) and CloudSat ice-only (gray); (b) VarCloud-OA radar (black) and CloudSat ice-only (gray); (c) VarCloud-OA radar (black) and VarCloud-SA radar (gray); (d) VarCloud-OA radar (black) and H06 (gray). Data are from October 2008 lognormal. Such distributions are highly skewed, with the factor difference between the mean and median increasing with the width of the distribution on the logarithmic scale.

A comparison between the VarCloud retrieval for all observations with the CloudSat ice-only retrieval in Fig. 5a reveals a similar distribution shape at temperatures that are warmer than $-50^{\circ} \mathrm{C}$ but a shift toward lower in-cloud IWC percentiles for the VarCloud retrieval at colder temperatures that is due to the inclusion of lidar-only retrievals of IWC, as seen in Fig. 4g. When the lidar-only retrievals are excluded from the VarCloud distribution in Fig. 5b, the CloudSat ice-only and VarCloud distributions are very similar for temperatures that are colder than $-10^{\circ} \mathrm{C}$ and between the 25th and 90th percentiles. The VarCloud-OA and VarCloud-SA retrievals have very similar distributions in Fig. 5c, although the latter appears to retrieve consistently higher IWC - up to 50\% higher than VarCloud-OA for a given percentile contour.

The in-cloud means of the various distributions, however, differ by up to a factor 4 , indicating that the mean IWC is highly sensitive to the top 5\% of the IWC distribution, which is where the mass-size relationships and radar scattering models are most uncertain. In radar retrievals, high IWC values are obtained only when high $Z_{e}$ is observed, which involves non-Rayleigh scattering and is treated differently by the retrievals as summarized in Table 1. Austin et al. (2009) acknowledge possible violations in the CloudSat retrieval of their assumptions for large particle sizes that are generally associated with high $Z_{e}$ values $\left(Z_{e}>20 \mathrm{~dB} Z\right)$, which may affect the high end of IWC values retrieved.

\section{Mean ratio between different ice water content retrievals}

The discussion of the IWC distribution in the previous section focused on differences between IWC retrievals through their overall statistics. This section instead focuses on the statistics of the differences in IWC between simultaneous retrievals. For the purpose of this discussion, we set the "control" product for all direct comparisons to be H06, because this retrieval can easily be reproduced once radar reflectivity and temperature data are available, and lidar data are not required.

To calculate the mean ratio $\mathcal{R}$, we actually average (indicated by angle brackets) over the logarithmic differences between two products and revert this average back to a linear scale as follows:

$$
\mathcal{R}=\exp \left\langle\ln \left(\frac{\mathrm{IWC}_{X}}{\mathrm{IWC}_{\text {control }}}\right)\right\rangle
$$



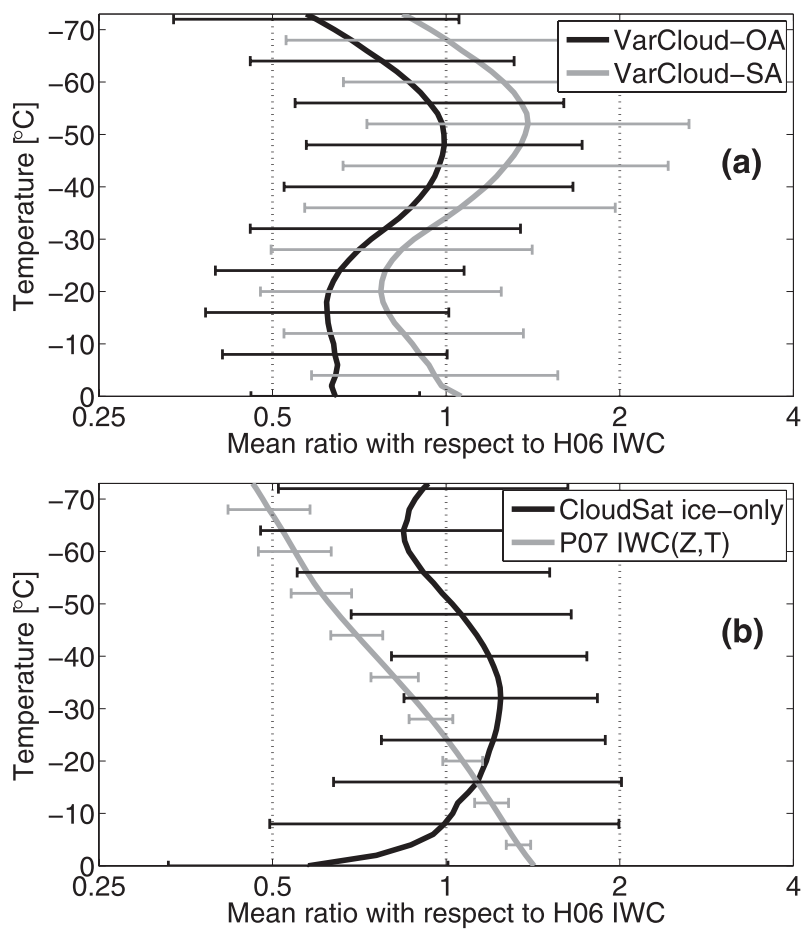

FIG. 6. Mean IWC ratio $\mathcal{R}$ given by Eq. (11) vs temperature. (a) Mean ratios with control H06 [Eq. (2)] and product-"X" VarCloud-OA (black) and VarCloud-SA (gray). (b) As in (a), but with product-"X" CloudSat ice-only (black) and P07 (gray). Rms differences are shown as error bars. Dotted lines show the $-50 \%, 0 \%$, and $+100 \%$ difference from left to right. Data are from October 2008.

with the rms differences in $\ln$ (IWC) derived similarly. Here, $X$ is one of VarCloud-OA, VarCloud-SA, CloudSat ice-only, or P07.

Because the CloudSat products are on a 240-m grid as opposed to the $60-\mathrm{m}$ grid for the VarCloud derived products, logarithmic differences are only calculated when both the CloudSat ice-only product retrieves IWC $>0$ and the products on the $60-\mathrm{m}$ vertical grid retrieve IWC $>0$ at the vertical level nearest to the CloudSat level. This effectively excludes VarCloud lidaronly retrievals. The mean and rms logarithmic differences are gathered for each temperature $T_{j}$ (per degree Celsius) and latitude $\phi_{k}$ (per $2^{\circ}$ ) and are subsequently weighted by $A_{k},\left\langle L_{k}\right\rangle$, and $\mathcal{P}\left(T_{j}\right)$ following Eq. (9). In Fig. 6 we show the mean ratios in IWC, given by Eq. (11). The variations with temperature of the mean ratio in IWC in Fig. 6 relate more to the differences in the in-cloud median rather than the in-cloud mean of the IWC distributions in Figs. 4 and 5. Although large differences among the in-cloud means appear in Fig. 5, they will have a small impact on the mean ratio in retrieved IWC between products because of their low occurrence as indicated by their location beyond the 90th percentiles. The mean ratio between the VarCloud-OA IWC retrieval and H06 is less than 1 at all temperatures, although they are within the rms difference from agreement. The slightly higher IWC retrievals from VarCloud-SA relative to VarCloud-OA in Fig. 5c are echoed in Fig. 6a, in which both products display a similar variation with temperature in their mean ratios with respect to $\mathrm{H} 06$ but the VarCloud-SA mean ratio is consistently higher than the VarCloud-OA mean ratio.

The CloudSat ice-only mean ratio with respect to $\mathrm{H} 06$ in Fig. 6b is generally larger than that for the VarCloud retrievals, although the two products can be seen to agree within their rms differences for all temperatures. The agreement between CloudSat ice-only and $\mathrm{H} 06$ for temperatures that are warmer than $-20^{\circ} \mathrm{C}$ is surprising given the considerably different distributions displayed in Figs. 4a,b. The relatively large rms differences indicate a large spread of the IWC ratios between these two products, however.

Large disagreement between P07 and H06 is evident for nearly all temperatures in Fig. 6b. From the formulas for H06 and P07, given by Eqs. (2) and (4), this difference appears from the coefficients for the temperatureonly dependence, which are -0.00706 and -0.0023 , respectively [units for both: $\log _{10}\left(\mathrm{~kg} \mathrm{~m}^{-3}\right){ }^{\circ} \mathrm{C}^{-1}$ ]. Accounting for the joint temperature-reflectivity coefficients in these formulas, for a fixed reflectivity, H06 will estimate IWC values that increase more rapidly as temperature decreases than do P07 estimates of IWC. For the coldest temperatures, lower IWC with P07 could be due to the inclusion of tropical cirrus in its dataset, whereas for warmer temperatures, higher IWC retrievals with P07 are likely because of the application of the Brown and Francis (1995) mass-diameter relationship with $D_{\text {max }}$ rather than $D_{\text {mean }}$.

As with the ice-cloud occurrences shown in Figs. 2 and 3, the mean ratios from Eq. (11) may depend on regional differences in ice-cloud distribution. The mean ratio comparison between different latitude bands is provided in Fig. 7. The ratios look similar for all three regions at temperatures warmer than $-50^{\circ} \mathrm{C}$ where the radar observes at least $50 \%$ of the ice clouds used for the retrieval. For the Southern Hemisphere midlatitudes, however, the VarCloud-OA and VarCloud-SA mean ratios with respect to $\mathrm{H} 06$ have both increased at the coldest temperatures (below $-50^{\circ} \mathrm{C}$ ) when compared with the other two regions. Note that very little ice cloud is observed by the radar at these colder temperatures in general, but also that the aircraft measurements from which H06 has been derived are from northern midlatitude ice cloud only. The dataset used in the derivation of P07 includes tropical cirrus, but a similar comparison using P07 as the control (not shown) indicated no different latitudinal dependence relative to Fig. 7, apart 

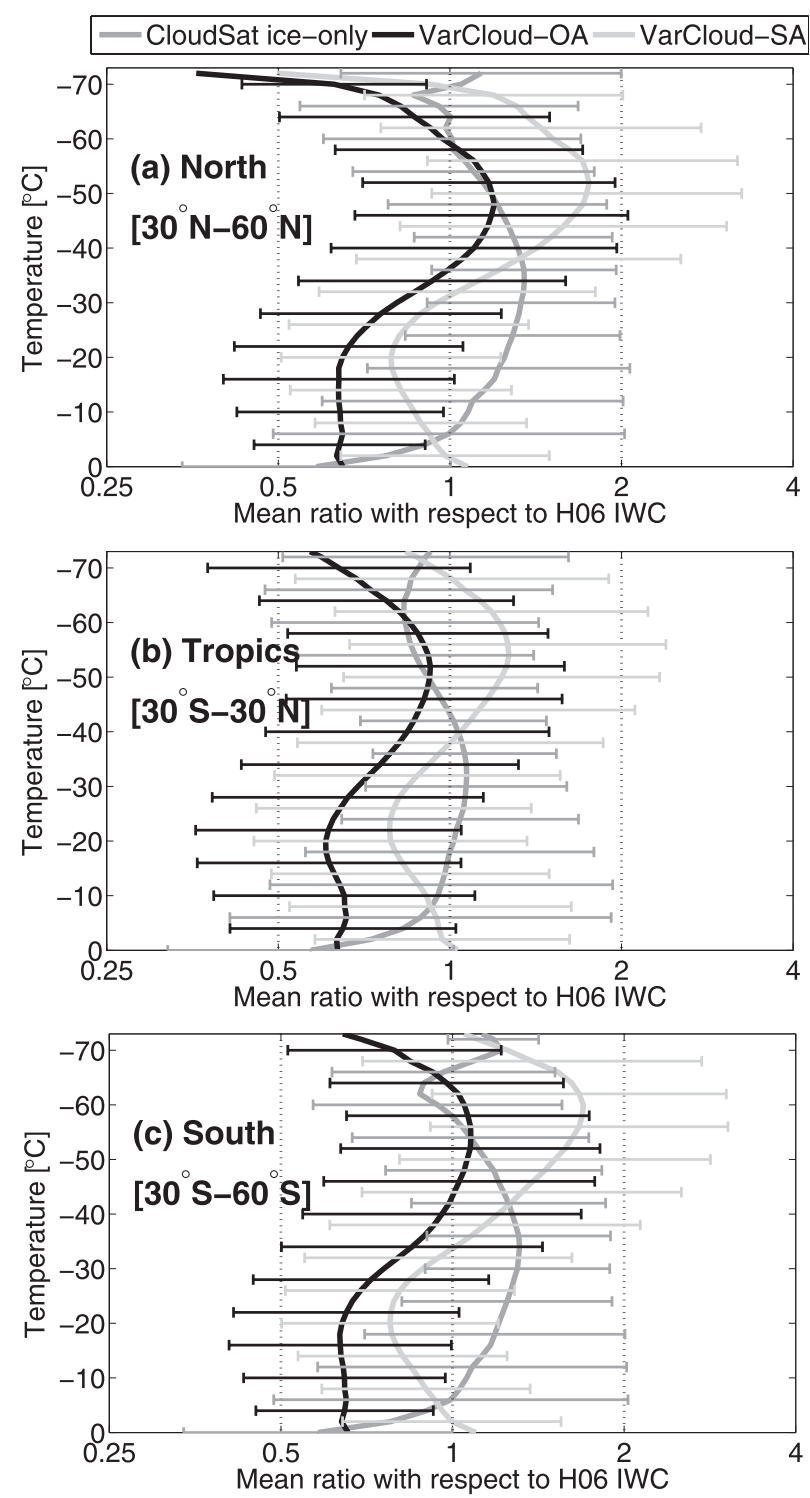

FIG. 7. Mean IWC ratio $\mathcal{R}$ with control H06 as in Fig. 6 split by different zonal regions (not showing P07). (a) Northern Hemisphere $30^{\circ}-60^{\circ} \mathrm{N}$, (b) tropics $30^{\circ} \mathrm{S}-30^{\circ} \mathrm{N}$, and (c) Southern Hemisphere $30^{\circ}-60^{\circ} \mathrm{S}$. Rms differences are shown as error bars. Dotted lines show the $-50 \%, 0 \%$, and $+100 \%$ difference from left to right. Data are from October 2008.

from the strong difference in temperature variation already apparent from Fig. 6 b.

In Fig. 8, the mean ratio in retrieved IWC given by Eq. (11) is shown with control H06, but now versus the radar reflectivity factor $Z_{e}$, which is obtained from the CloudSat observations using Eq. (3). The mean ratio between $\mathrm{H} 06$ and $\mathrm{P} 07$ varies less strongly with reflectivity than with temperature, because their coefficients for the reflectivity-only dependence in Eqs. (2) and (4) are similar: 0.0923 and $0.0939 \log _{10}\left(\mathrm{~kg} \mathrm{~m}^{-3}\right) \mathrm{dBZ}^{-1}$. CloudSat
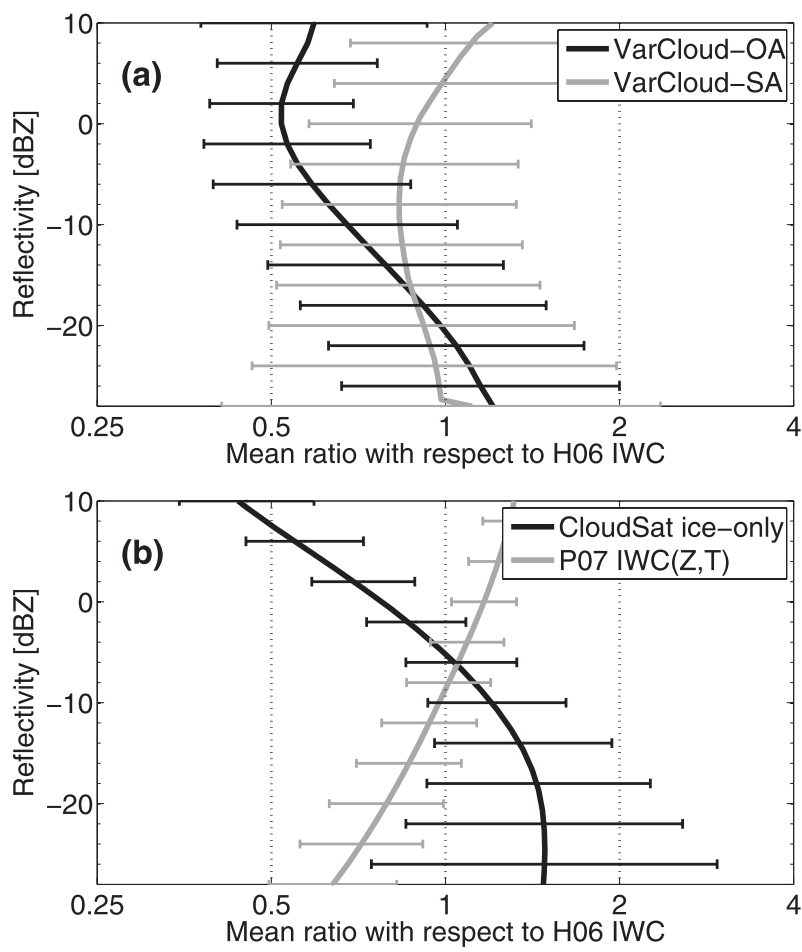

FIG. 8. (a) Mean IWC ratio $\mathcal{R}$ vs radar reflectivity factor $Z_{e}$ (dBZ). Shown are the ratios with control H06 for VarCloud-OA (black) and VarCloud-SA (gray). (b) As in (a), but with CloudSat ice-only (black) and P07 (gray). Rms differences are shown as error bars. Dotted lines show the $-50 \%, 0 \%$, and $+100 \%$ difference from left to right. Data are from October 2008.

ice-only and VarCloud show good agreement with $\mathrm{H} 06$ for lower reflectivities $\left(Z_{e}<-10 \mathrm{dBZ}\right)$ within their mean rms differences. The maximum mean ratio between the CloudSat ice-only IWC retrieval and the VarCloudOA retrieval is approximately 1.5 for $Z_{e}<-10 \mathrm{~dB} Z$.

Reflectivity dependence is shown for reflectivities up to $10 \mathrm{~dB} Z$, for only a few reflectivities larger than $10 \mathrm{dBZ}$ occur in the dataset from which H06 has been derived Hogan et al. (2006b). At high reflectivities $\left(Z_{e}>0 \mathrm{dBZ}\right)$, the VarCloud-SA product shows the best agreement with $\mathrm{H} 06$, which can be expected since both retrievals explicitly assume that all particles are spheres and they apply the same mass-size relationship. The VarCloud-OA product models ice particles as oblate spheroids for radar scattering, which in the non-Rayleigh scattering regime implies a lower IWC for the same reflectivity. This can be seen in Fig. 8 as a shift to lower ratios relative to the VarCloud-SA ratios for high reflectivities where non-Rayleigh scattering is likely to occur. The CloudSat ice-only product deviates from $\mathrm{H} 06$ most notably at these high reflectivities, which is likely due to the difference in treatment of non-Rayleigh scattering. 


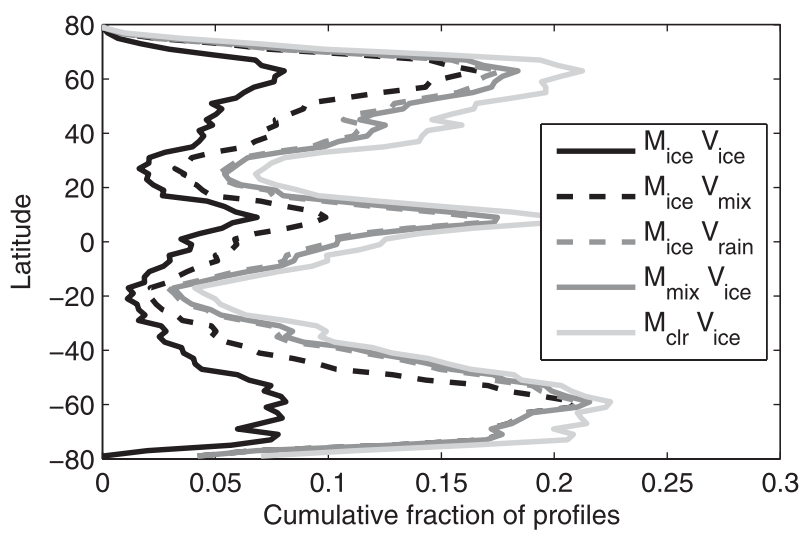

FIG. 9. Overview of joint MODIS ("M") and VarCloud ("V") observations of ice clouds for daytime overpasses in October 2008. Cumulative fraction of total number of profiles is shown vs latitude, with combinations of cloud phase retrievals: 1) MODIS and VarCloud retrieve ice-only; 2) MODIS retrieves ice, but VarCloud also retrieves liquid (no rain); 3) MODIS retrieves ice, but VarCloud determines that there is rain in the profile; 4) VarCloud observes an ice-only profile, but MODIS retrieves a mixed, liquid, or undetermined cloud phase; 5) VarCloud observes an ice-only profile, but MODIS determines a clear profile.

\section{Vertically integrated ice-cloud properties}

The previous sections dealt with the vertical structure of cloud properties derived from CloudSat and CALIPSO observations. For GCM evaluations such as Waliser et al. (2009) and for retrievals from different satellites such as MODIS, the vertical structure of ice clouds may be largely unknown and instead the vertically integrated cloud properties are used for comparison. In this section, VarCloud profiles of IWC and $\alpha_{v}$ are compared with MODIS retrievals of IWP and $\tau$, as well as $\left\langle r_{e}\right\rangle$, although some precautions are necessary to ascertain a like-with-like comparison.

First, MODIS only retrieves cloud-ice properties for a 1-km observation pixel when it has determined an icecloud phase. The full cloud column is then assumed to consist of ice, so that the measured reflectances associated with the cloud column are attributed to ice-cloud optical depth and ice water path. VarCloud, however, can distinguish liquid clouds and rain underneath ice clouds and will only retrieve ice properties for the part of the cloud that it determines to be ice phase. Furthermore, profiles that only contain subvisual cirrus are likely to be detected as ice-only by VarCloud but may be missed by MODIS. The occurrences of these possible mismatches in ice-cloud determination are summarized by their cumulative fraction of all profiles versus latitude for daytime observations in Fig. 9. Only the fraction of profiles indicated by the solid black line in this figure (MODIS and VarCloud both diagnose ice-only cloud) will be used to generate the statistics in this section. Note that we also exclude observations over Antarctica and Greenland, for the MODIS retrievals will be strongly affected by their bright surfaces in the visible range (King et al. 2004).

Second, MODIS estimates IWP from its $\tau$ and $\left\langle r_{e}\right\rangle$ retrievals using Eq. (5), where $\left\langle r_{e}\right\rangle$ is dominated by the top four or five optical depths and will therefore not be representative of thicker clouds (Kokhanovsky 2004). Any differences emerging from the MODIS IWP comparison with the full VarCloud IWC profiles may therefore be due to the application of this method. This section will include a comparison between IWP estimated using the MODIS method from Eq. (5) on the VarCloud $\tau$ and $\left\langle r_{e}\right\rangle$ and IWP obtained from the VarCloud IWC profiles.

Figure 10 shows the zonal mean of $\tau,\left\langle r_{e}\right\rangle$, and IWP for VarCloud-OA, VarCloud-BR, and MODIS, using only jointly observed ice-only values. Zhang et al. (2009) showed that optical depth retrievals from Polarization and Directionality of the Earth's Reflectances (POLDER) were lower than simultaneous MODIS retrievals, with the mean ratio between the two products being 0.81 , whereas much better agreement between the two products was achieved after adjusting the POLDER ice particle model to that used by the MODIS product. We consider a similar adjustment by introducing the VarCloud-BR retrieval, which assumes a bullet rosette shape for ice particles instead of the Brown and Francis (1995) assumption in VarCloud-OA. VarCloud-BR is not considered to be a more appropriate method than VarCloud-OA, however, because the assumption of bullet rosettes throughout the ice-cloud profile would not provide a good fit to radar observations from H06 in the temperature range from $0^{\circ}$ to $-40^{\circ} \mathrm{C}$, whereas the method of Brown and Francis (1995) performs very well (Hogan et al. 2006b). The change to VarCloud-BR leads to higher retrievals of the visible extinction coefficient $\alpha_{v}$ by factors of 2 or more in radar-only observations relative to VarCloud-OA. Since radar-only observations dominate optical depth retrievals for optically thick clouds, which in turn dominate the zonal means in Fig. 10a, the VarCloud-BR zonal mean $\tau$ is considerably higher than that of VarCloud-OA by factors of 2 and higher but does not provide a better match with MODIS.

In the VarCloud microphysical model, particle size is described by the effective radius (Foot 1988), given by

$$
r_{e}=\frac{3}{2} \frac{\mathrm{IWC}}{\rho_{\mathrm{ice}} \alpha_{v}}
$$

where $\rho_{\text {ice }}=917 \mathrm{~kg} \mathrm{~m}^{-3}$ is the density of ice. Using Eq. (12) and the direct comparison between VarCloud$\mathrm{OA}$ and VarCloud-BR retrievals of IWC and $\alpha_{v}$ by 

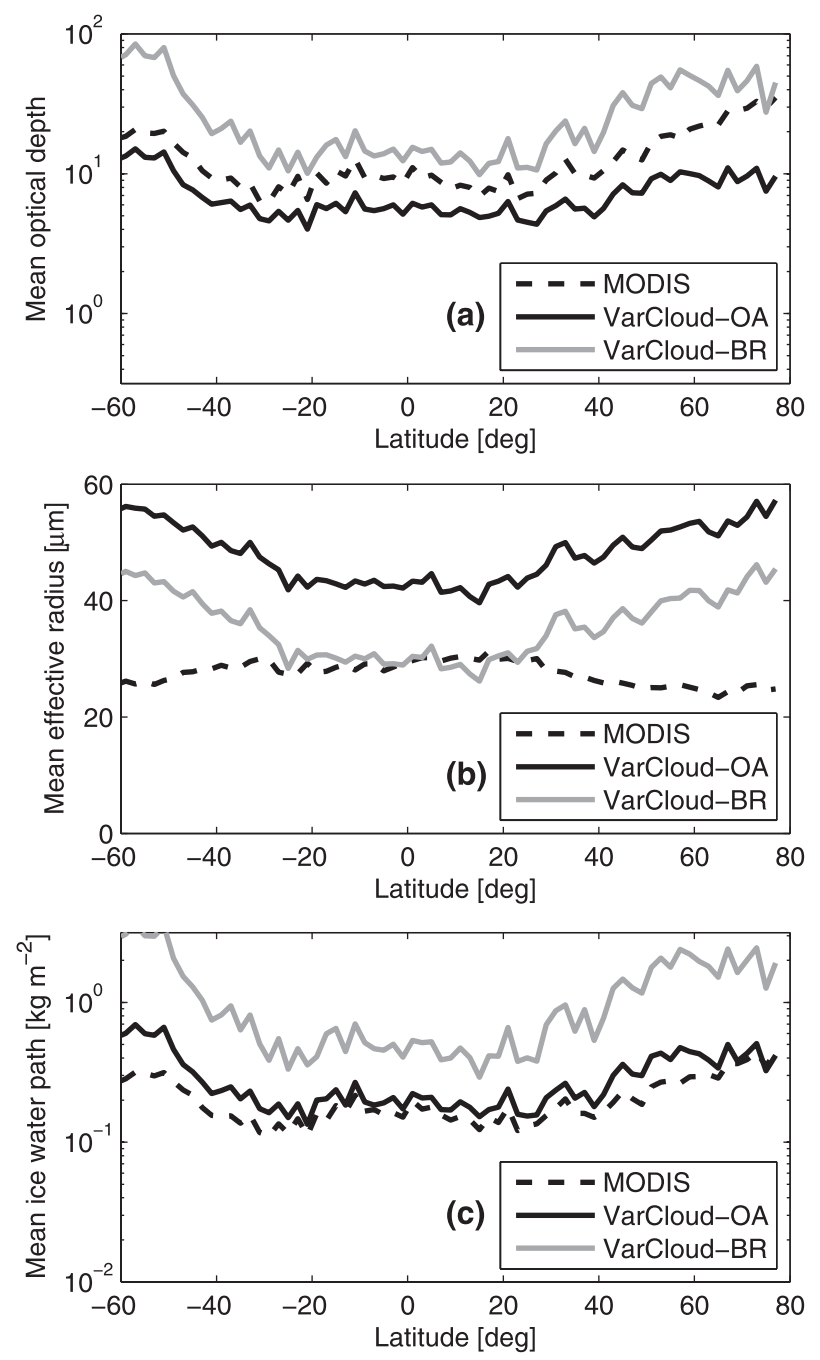

FIG. 10. An ice-cloud-only comparison among MODIS (dashed), VarCloud-OA (black), and VarCloud-BR (gray) retrievals of (a) $\tau$, (b) $\left\langle r_{e}\right\rangle$, and (c) IWP, showing the in-cloud zonal averages for October 2008. Only joint observations of ice-only profiles are included.

Delanoë and Hogan (2010), lower $r_{e}$ retrievals can be expected from VarCloud-BR than from VarCloud-OA. In Fig. 10b, the VarCloud-OA zonal average of $\left\langle r_{e}\right\rangle$ indeed appears to be consistently higher than VarCloudBR by about $10 \mu \mathrm{m}$. The VarCloud-BR zonal average is comparable to the MODIS average in the tropics, but they differ by a factor of up to 2 in the midlatitudes. A restriction of the VarCloud $\left\langle r_{e}\right\rangle$ to only include $r_{e}$ retrievals from the top five ice-cloud optical depths of the clouds reduces zonal means of $\left\langle r_{e}\right\rangle$ by roughly $6 \mu \mathrm{m}$ on average for VarCloud-BR and $4 \mu \mathrm{m}$ for VarCloud-OA, although no better overall agreement with MODIS is found.

The differences between the products observed for the in-cloud zonal averages of $\tau$ and $\left\langle r_{e}\right\rangle$ do not simply translate to the IWP comparison of Fig. 10c. VarCloudOA provides good agreement within a factor 2 with MODIS in Fig. 10c - in particular, in the tropics-despite the generally poor agreement in $\tau$ and $\left\langle r_{e}\right\rangle$. In contrast, factors of 3 or more difference between MODIS and VarCloud-BR occur even in the tropics, where $\tau$ and $\left\langle r_{e}\right\rangle$ showed reasonable agreement.

The differences in zonal means of Fig. 10 cannot immediately be attributed to instrument and algorithm sensitivities. Instead, in Fig. 11 we provide histograms of joint probability distributions from direct comparisons of individual retrievals by MODIS, VarCloud-OA, and VarCloud-BR. The shape of the distribution in Fig. 11a is aligned with a fixed ratio between the MODIS and VarCloud-OA retrievals of $\tau$, with peak occurrences indicating that MODIS $\tau$ values are consistently higher than VarCloud-OA by approximately a factor of 2, which explains the difference in zonal mean $\tau$ from Fig. 10a. For VarCloud-BR, the peak occurrences in the joint distribution in Fig. 11b spread from retrievals of low $\tau$ that agree well with MODIS results to retrievals that are a factor of 2 higher than those from MODIS. Differences in high- $\tau$ retrievals between the two VarCloud products are consistent with the differences in $\alpha_{v}$ for radar-only retrievals illustrated by Delanoë and Hogan (2010).

There is no obvious linear fit when comparing MODIS and VarCloud retrievals of $\left\langle r_{e}\right\rangle$ in Figs. 11c,d. For VarCloud-BR, the joint distribution with MODIS of individual $\left\langle r_{e}\right\rangle$ retrievals has its peak stretched toward a ratio of 1 between the two products in Fig. 11d as compared with the distribution with VarCloud-OA in Fig. 11c, but the overall shape of the distributions indicates a tendency of MODIS retrievals to lie between 10 and $40 \mu \mathrm{m}$, whereas both VarCloud products regularly retrieve $\left\langle r_{e}\right\rangle$ above $50 \mu \mathrm{m}$. MODIS retrievals of $\left\langle r_{e}\right\rangle$ are dominated by cloud top, yet a restriction of VarCloud $\left\langle r_{e}\right\rangle$ to the top five ice-cloud optical depths (not shown) only marginally narrows the joint distributions relative to Figs. 11c,d because of a slight reduction in VarCloud retrievals of large $\left\langle r_{e}\right\rangle$. Hence the sensitivity to cloud top does not explain the basic difference between MODIS and VarCloud.

The good comparison in IWP between MODIS and VarCloud-OA in Fig. 10c is reflected in Fig. 11e, where the joint distribution is centered around a ratio of 1 , with slightly higher VarCloud retrievals of high IWP, which explain the difference in zonal mean. The higher zonal averages for VarCloud-BR in Fig. 10c relative to MODIS and VarCloud-OA can be inferred from Fig. 11f. Although reasonable agreement between MODIS and VarCloud$\mathrm{BR}$ is found for low-IWP retrievals, the latter retrieves IWP that are higher than those of MODIS by a factor of 2 or more for high-IWP retrievals. 

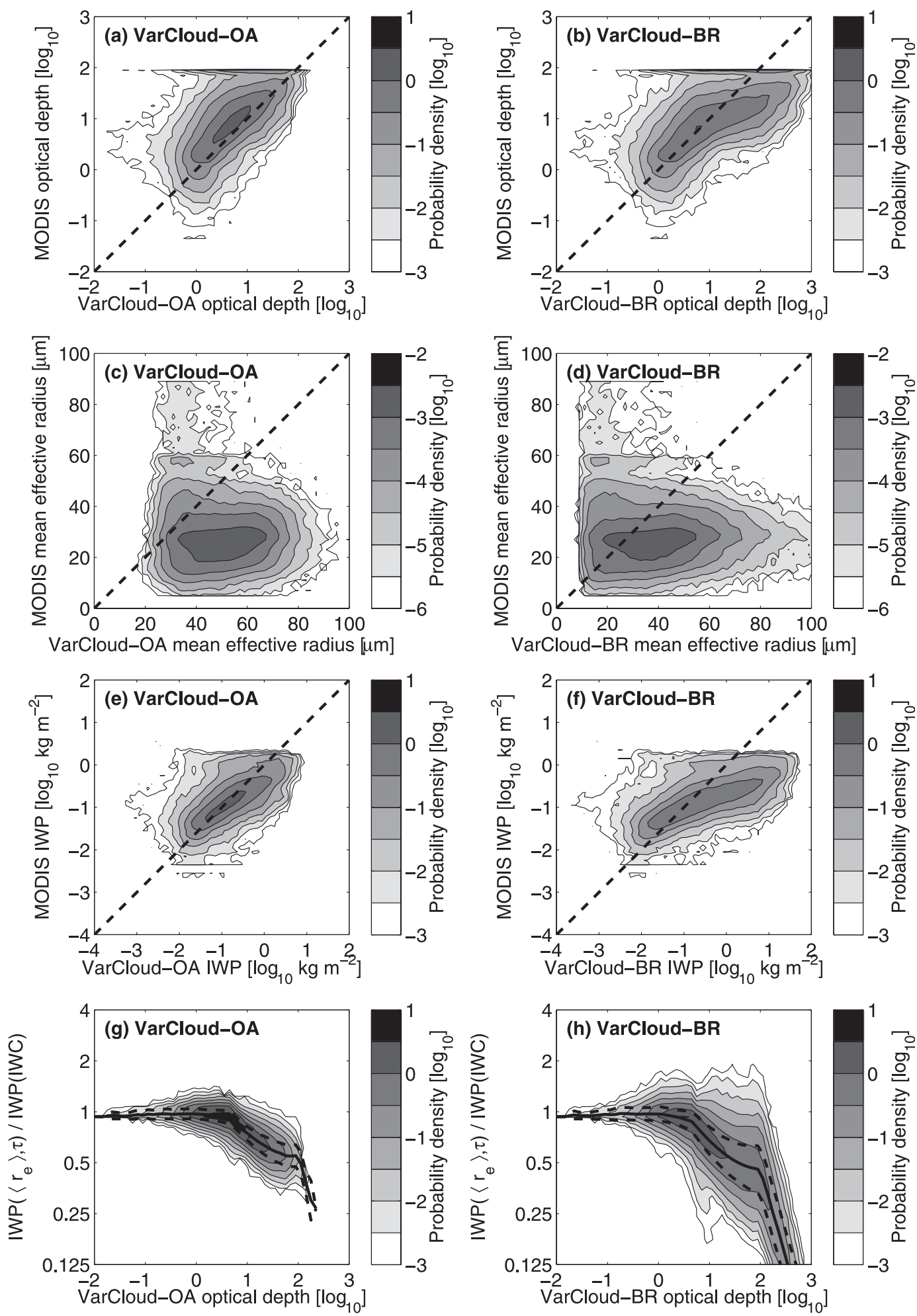

FIG. 11. An ice-cloud-only comparison between MODIS and VarCloud for joint ice-cloud retrievals in terms of $\tau$ with (a) VarCloud-OA and (b) VarCloud-BR; in terms of $\left\langle r_{e}\right\rangle$ with (c) VarCloud-OA and (d) VarCloud-BR; and in terms of IWP with (e) VarCloud-OA and (f) VarCloud-BR. A comparison between IWP retrievals showing the ratio between IWP retrieved using Eq. (5) with $\left\langle r_{e}\right\rangle$ for the top five cloud optical depths and $\max (\tau)<100$, divided by IWP as the integral over IWC, vs VarCloud retrievals of $\tau$, for (g) VarCloud-OA and (h) VarCloud-BR. Data are from October 2008, and only joint observations of ice-only profiles are included. Dashed lines in (a)-(f) indicate the 1:1 ratio. Solid lines in $(\mathrm{g})$ and $(\mathrm{h})$ show the mean ratio, and dashed lines show rms differences. Probability densities are per $\left(\log _{10}\right)^{2}$ for $\tau$, per $(\mu \mathrm{m})^{2}$ for $\left\langle r_{e}\right\rangle$, per $\left[\log _{10}\left(\mathrm{~kg} \mathrm{~m}^{-2}\right)\right]^{2}$ for IWP, and per $\left(\log _{10} \log _{2}\right)$ for mean IWP ratio vs $\tau$. 
With the VarCloud retrievals it is possible to derive IWP from $\tau$ and $\left\langle r_{e}\right\rangle$ using Eq. (5), simulating the method used by MODIS. For liquid water clouds in the boundary layer, a similar method to Eq. (5) exists to derive liquid water path from optical depth and effective radius (derived from cloud top), but an adjusted model is used to account for variations of liquid water content and effective radius with height (Wood and Hartmann 2006). Such adjustments for ice clouds to Eq. (5) could improve the IWP comparison between MODIS and VarCloud, and in Figs. 11g,h we show the difference between a retrieval using Eq. (5) and IWP as the integral of IWC, both from VarCloud profiles only. Zhang et al. (2010) performed a similar comparison between the MODIS method of retrieving IWP and synthetic cloud profiles with optical thickness up to 7 and found that mean effective radius and ice water path retrievals were preferentially weighted toward cloud top. When applying Eq. (5) to VarCloud profiles, we therefore restrict $\left\langle r_{e}\right\rangle$ to $r_{e}$ retrievals from the top five optical depths of ice clouds, whereas $\tau$ is restricted to a maximum value of 100 , thus applying the MODIS sensitivity restrictions. In Figs. 11g,h, both VarCloud retrievals show that for $\tau$ up to about 10 the two methods for IWP retrieval agree to within one rms difference of 1, comparable to the results from Zhang et al. (2010). The IWP method using Eq. (5) retrieves on average lower values than the integral over IWC for $\tau$ larger than 10, reaching a mean difference of a factor of 2 or larger between the two methods once $\tau$ exceeds 100. The assumption of ice-cloud profiles with constant $r_{e}$ in Eq. (5) breaks down when the cloud has a distinct and significant vertical structure, which follows from the inequality below:

$$
\begin{aligned}
\mathrm{IWP} & =\sum_{j}\left(\mathrm{IWC}_{j} \times \Delta z\right)=\frac{2}{3} \rho_{\text {ice }} \sum_{j}\left(r_{e, j} \alpha_{v, j} \times \Delta z\right) \\
& \neq \frac{2}{3} \rho_{\text {ice }}\left\langle r_{e}\right\rangle \tau .
\end{aligned}
$$

Thus, for $\tau>10$, the different IWP retrieval methods explain the VarCloud overestimates of high IWP in Figs. 11e,f and consequently the increase in zonal mean IWP in Fig. 10c relative to MODIS. For thin ice clouds, however, $\left\langle r_{e}\right\rangle$ is a better characterization of mean particle size for the full cloud-ice column, and Figs. 11g,h show that the two methods agree well.

\section{Conclusions}

A combined radar-lidar cloud-ice retrieval using CloudSat and CALIPSO measurements (Delanoë and Hogan 2010), VarCloud, has been compared with coincident cloud-ice retrievals from the A-Train satellites.
The advantages of a multi-instrument algorithm have been illustrated by the larger fraction of ice cloud observed by the combination of radar and lidar than by the single instruments, as well as the greater range of IWC values obtained as a result of the different sensitivities of each instrument.

The radiative impact of ice clouds depends on their full IWC distribution, not just the mean or integrated values (IWP), which will be weighted by the most optically thick (parts of the) ice clouds. The retrievals that provide IWC profiles have been shown to produce similar IWC distributions with temperature, with typical differences of the in-cloud median IWC of less than $50 \%$. Differences of a factor of 2-7 in mean IWC values between the retrievals were shown to be dominated by retrievals of high IWC with low occurrence, due to differences between the methods in the treatment of non-Rayleigh scattering for observations of high $Z_{e}$. Further evaluation of radar scattering models with in situ measurements will be necessary to constrain high IWC values.

Retrievals from passive and active satellite observations were compared using MODIS and VarCloud for joint observations with ice-only cloud profiles. A change in the VarCloud ice particle model did not explain the large spread in the joint distribution of $\left\langle r_{e}\right\rangle$. A restriction of VarCloud retrievals of $\left\langle r_{e}\right\rangle$ to the top five optical depths of ice cloud reduced $\left\langle r_{e}\right\rangle$ slightly but again had no impact on the large spread of the distribution. The IWP comparison of MODIS with VarCloud-BR indicated a larger spread in IWP from the latter retrieval, which was explained by underestimates of IWC for lidar-only observations and overestimates for radar-only observations when bullet rosettes are used relative to when oblate aggregates are used. A direct comparison of different IWP retrieval methods using the VarCloud profiles showed that an IWP retrieval using $\tau$ and $\left\langle r_{e}\right\rangle$ was in good agreement with the IWC profile for $\tau<10$ but was reduced by a factor of 2 or more when $\tau>100$.

The sensitivity of VarCloud to its ice particle model (a sensitivity shared by almost all ice-cloud retrievals) indicated that these assumptions partly explain differences with MODIS retrievals, whereas differences in IWP for high $\tau$ were also affected by the IWP retrieval method. The poor agreement in $\left\langle r_{e}\right\rangle$ between MODIS and VarCloud indicated a large uncertainty for this variable arising from the satellite and algorithm sensitivities, with MODIS assuming a constant multiple-habit ice particle distribution throughout the profile, determined by particle size measurements near the cloud top, and VarCloud assuming a single-habit ice particle distribution with sizes that may vary throughout the cloud column. The lack of agreement in $\left\langle r_{e}\right\rangle$ for thin ice cloud-where MODIS reflectances can be assumed to come from the entire cloud column and 
where the MODIS IWP retrieval method for VarCloud shows good agreement with the full IWC profile-indicated that further cross validation of these satellite retrievals requires a greater flexibility to test with different ice particle models within each algorithm.

Acknowledgments. We thank the ICARE Data and Services Center for their assistance, development support, and data processing for the VarCloud product. VarCloud retrievals are available at http://www.icare. univ-lille1.fr/projects/dardar/. CALIPSO lidar data used are available at http://eosweb.larc.nasa.gov/. The official CloudSat data products are available at http://cloudsat. cira.colostate.edu/ and are provided by the NASA CloudSat project. MODIS products are available online at http://modis-atmos.gsfc.nasa.gov/ and are provided by the MODIS Science Team. This work has been funded by NERC Grants NE/E00525X/1, NE/C519697/1, and NE/H003894/1.

\section{REFERENCES}

Anselmo, T., and Coauthors, 2007: Cloud Aerosol Lidar Infrared Pathfinder Satellite Observations (CALIPSO). Data management system and data products catalog, NASA Langley Research Center Doc. PC-SCI-503 (release 2.4), 100 pp. [Available online at http://ccplot.org/pub/resources/CALIPSO/ PC-SCI-503\%20CALIPSO \%20Data\%20Products\%20Catalog. pdf.]

Austin, R. T., A. J. Heymsfield, and G. L. Stephens, 2009: Retrieval of ice cloud microphysical parameters using the CloudSat millimeter-wave radar and temperature. J. Geophys. Res., 114, D00A23, doi:10.1029/2008JD010049.

Baum, B. A., A. J. Heymsfield, P. Yang, and S. T. Bedka, 2005a: Bulk scattering properties for the remote sensing of ice clouds. Part I: Microphysical data and models. J. Appl. Meteor., 44, 1885-1895.

— , P. Yang, A. J. Heymsfield, S. Platnick, M. D. King, Y.-X. Hu, and S. T. Bedka, 2005b: Bulk scattering properties for the remote sensing of ice clouds. Part II: Narrowband models. J. Appl. Meteor., 44, 1896-1911.

Benedetti, A., G. L. Stephens, and J. M. Haynes, 2003: Ice cloud microphysics retrievals from millimeter radar and visible optical depth using an estimation theory approach. J. Geophys. Res., 108, doi:10.1029/2002JD002693.

Bodas-Salcedo, A., M. J. Webb, M. E. Brooks, M. A. Ringer, K. D. William, S. F. Milton, and D. R. Wilson, 2008: Evaluating cloud systems in the Met Office global forecast model using simulated CloudSat radar reflectivities. J. Geophys. Res., 113, D00A13, doi:10.1029/2007JD009620.

Brown, P. R. A., and P. N. Francis, 1995: Improved measurements of the ice water content in cirrus using a total-water probe. J. Atmos. Oceanic Technol., 12, 410-414.

Delanoë, J., and R. J. Hogan, 2008: A variational scheme for retrieving ice cloud properties from combined radar, lidar, and infrared radiometer. J. Geophys. Res., 113, D07204, doi:10.1029/ 2007JD009000.

- , and - 2010: Combined CloudSat-CALIPSO-MODIS retrievals of the properties of ice clouds. J. Geophys. Res., 115, D00H29, doi:10.1029/2009JD012346.
—, A. Protat, J. Testud, D. Bouniol, A. J. Heymsfield, A. Bansemer, P. R. A. Brown, and R. M. Forbes, 2005: Statistical properties of the normalized ice particle size distribution. J. Geophys. Res., 110, D10201, doi:10.1029/2004JD005405.

Donovan, D. P., and Coauthors, 2001: Cloud effective particle size and water content profile retrievals using combined radar and lidar observations 2 . Comparison with IR radiometer and in situ measurements of ice clouds. J. Geophys. Res., 106, 27 449-27 464.

Foot, J. S., 1988: Some observations of the optical properties of clouds-2. Cirrus. Quart. J. Roy. Meteor. Soc., 114, 145-164.

Francis, P. N., P. Hignett, and A. Macke, 1998: The retrieval of cirrus cloud properties from aircraft multi-spectral reflectance measurements during EUCREX'93. Quart. J. Roy. Meteor. Soc., 124, 1273-1291.

Heymsfield, A. J., and Coauthors, 2008: Testing IWC retrieval methods using radar and ancillary measurements with in situ data. J. Appl. Meteor. Climatol., 47, 135-163.

Hogan, R. J., 2006: Fast approximate calculation of multiply scattered lidar returns. Appl. Opt., 45, 5984-5992.

_ 2008: Fast lidar and radar multiple-scattering models. Part I: Small-angle scattering using the photon variance-covariance method. J. Atmos. Sci., 65, 3621-3635.

— wavelength radar to make global measurements of cirrus clouds. J. Atmos. Oceanic Technol., 16, 518-531.

- P. N. Francis, H. Flentje, A. J. Illingworth, M. Quante, and J. Pelon, 2003: Characteristics of mixed-phase clouds. I: Lidar, radar and aircraft observations from CLARE'98. Quart. J. Roy. Meteor. Soc., 129, 2089-2116.

—, D. P. Donovan, C. Tinel, M. A. Brooks, D. Bouniol, A. J. Illingworth, and J. P. V. Poiares Baptista, 2006a: Independent evaluation of the ability of spaceborne radar and lidar to retrieve the microphysical and radiative properties of clouds. J. Atmos. Oceanic Technol., 23, 211-227.

— M. P. Mittermaier, and A. J. Illingworth, 2006b: The retrieval of ice water content from radar reflectivity factor and temperature and its use in evaluating a mesoscale model. J. Appl. Meteor., 45, 301-317.

Hu, Y., and Coauthors, 2007: The depolarization-attenuated backscatter relation: CALIPSO lidar measurements vs. theory. Opt. Express, 15, 5327-5332.

Intrieri, J. M., G. L. Stephens, W. L. Eberhart, and T. Uttal, 1993: A method for determining cirrus cloud particle sizes using lidar and radar backscatter techniques. J. Appl. Meteor., 32, 1074 1082.

King, M. D., S.-C. Tsay, S. E. Platnick, M. Wang, and K. N. Liou, 1997: Cloud retrieval algorithms for MODIS: Optical thickness, effective particle radius, and thermodynamic phase. NASA MODIS Algorithm Theoretical Basis Doc. ATBD-MOD-05, 83 pp. [Available online at http://modis.gsfc.nasa.gov/data/atbd/ atbd_mod05.pdf.]

_ S. Platnick, P. Yang, G. T. Arnold, M. A. Gray, J. C. Riedi, S. A. Ackerman, and K.-N. Liou, 2004: Remote sensing of liquid water and ice cloud optical thickness and effective radius in the Arctic: Application of airborne multispectral MAS data. J. Atmos. Oceanic Technol., 21, 857-875.

, P. A. Hubanks, G. T. Arnold, E. G. Moody, G. Wind, and B. Wind, 2006: Collection 005 change summary for the MODIS cloud optical property (06_OD) algorithm (version 3.1.1). NASA Collection 005 Change Summary Doc., 23 pp. [Available online at http://modis-atmos.gsfc.nasa.gov/C005_ Changes/C005_CloudOpticalProperties_ver311.pdf.] 
Kokhanovsky, A. A., 2004: The depth of sunlight penetration in cloud fields for remote sensing. IEEE Geosci. Remote Sens. Lett., 1, 242-245.

Mace, G. G., 2004: Level 2 GEOPROF product process description and interface control document (version 3.0). Cooperative Institute for Research in the Atmosphere Rep., 43 pp. [Available online at http://www.cloudsat.cira.colostate.edu/ ICD/2B-GEOPROF/2B-GEOPROF_PDICD_3.0.pdf.]

—, Q. Zhang, M. Vaughn, R. Marchand, G. Stephens, C. Trepte, and D. Winker, 2009: A description of hydrometeor layer occurrence statistics derived from the first year of merged CloudSat and CALIPSO data. J. Geophys. Res., 114, D00A26, doi:10.1029/2007JD009755.

McFarquhar, G. M., and A. J. Heymsfield, 1998: The definition and significance of an effective radius for ice clouds. J. Atmos. Sci., 55, 2039-2041.

Mitchell, D. L., 1996: Use of mass- and area-dimensional power laws for determining precipitation particle terminal velocities. J. Atmos. Sci., 53, 1710-1723.

Mitrescu, C., J. M. Haynes, G. L. Stephens, S. D. Miller, G. M. Heymsfield, and M. J. McGill, 2005: Cirrus cloud optical, microphysical, and radiative properties observed during the CRYSTAL-FACE experiment. J. Geophys. Res., 110, D09208, doi:10.1029/2004JD005605.

Noel, V., and H. Chepfer, 2010: A global view of horizontally oriented crystals in ice clouds from Cloud-Aerosol Lidar and Infrared Pathfinder Satellite Observation (CALIPSO). J. Geophys. Res., 115, D00H23, doi:10.1029/2009JD012365.

Okamoto, H., S. Iwasaki, M. Yasui, H. Horie, H. Kuroiwa, and H. Kumagai, 2003: An algorithm for retrieval of cloud microphysics using 95-GHz cloud radar and lidar. J. Geophys. Res., 108, 4226, doi:10.1029/2001JD001225.

Platnick, S., 2000: Vertical photon transport in cloud remote sensing problems. J. Geophys. Res., 105, 22 919-22 935.

—, M. D. King, S. A. Ackerman, W. P. Menzel, B. A. Baum, J. C. Riédi, and R. A. Frey, 2003: The MODIS cloud products: Algorithms and examples from Terra. IEEE Trans. Geosci. Remote Sens., 41, 459-473.

Protat, A., J. Delanoë, D. Bouniol, A. J. Heymsfield, A. Bansemer, and P. Brown, 2007: Evaluation of ice water content retrievals from cloud radar reflectivity and temperature using a large airborne in site microphysical database. J. Appl. Meteor. Climatol., 46, 557-572.

Rodgers, C. D., 2000: Inverse Methods for Atmospheric Sounding: Theory and Practice. World Scientific, 238 pp.

Stephens, G. L., S.-C. Tsay, P. W. Stackhouse, and P. J. Flatau, 1990: The relevance of microphysical and radiative properties of cirrus clouds to climate and climate feedback. J. Atmos. Sci., 47, 1742-1753.

- and Coauthors, 2002: The CloudSat mission and the A-Train. Bull. Amer. Meteor. Soc., 83, 1771-1790.
— - and Coauthors, 2008: CloudSat mission: Performance and early science after the first year of operation. J. Geophys. Res., 113, D00A18, doi:10.1029/2008JD009982.

Tanelli, S., S. L. Durden, E. Im, K. S. Pak, D. G. Reinke, P. Partain, J. M. Haynes, and R. T. Marchand, 2008: CloudSat's cloud profiling radar after two years in orbit: Performance, calibration, and processing. IEEE Trans. Geosci. Remote Sens., 46, 3560-3573.

Tinel, C., J. Testud, R. J. Hogan, A. Protat, J. Delanoë, and D. Bouniol, 2005: The retrieval of ice cloud properties from cloud radar and lidar synergy. J. Appl. Meteor., 44, 860-875.

Waliser, D. E., and Coauthors, 2009: Cloud ice: A climate model challenge with signs and expectations of progress. J. Geophys. Res., 114, D00A21, doi:10.1029/2008JD010015.

Warren, S. G., and C. J. Hahn, 2002: Clouds: Climatology. Encyclopedia of the Atmospheric Sciences, Academic Press, 476-483.

Winker, D. M., 2003: Accounting for multiple scattering in retrievals from space lidar. 12th International Workshop on Lidar Multiple Scattering Experiments, C. Werner, U. G. Oppel, and T. Rother, Eds., International Society for Optical Engineering (SPIE Proceedings, Vol. 5059), 128-139.

, J. Pelon, and M. P. McCormick, 2003: The CALIPSO mission: Spaceborne lidar for observation of aerosols and clouds. Lidar Remote Sensing for Industry and Environment Monitoring III, U. N. Singh, T. Itabe, and Z. Liu, Eds., International Society for Optical Engineering (SPIE Proceedings, Vol. 4893), 1-11.

, M. A. Vaughan, A. Omar, Y. Hu, K. A. Powell, Z. Liu, W. H. Hunt, and S. A. Young, 2009: Overview of the CALIPSO mission and CALIOP data processing algorithms. J. Atmos. Oceanic Technol., 26, 2310-2323.

Wood, R., and D. L. Hartmann, 2006: Spatial variability of liquid water path in marine low cloud: The importance of mesoscale cellular convection. J. Climate, 19, 1748-1764.

Wu, D. L., and Coauthors, 2009: Vertical distributions and relationships of cloud occurrence frequency as observed by MISR, AIRS, MODIS, OMI, CALIPSO, and CloudSat. Geophys. Res. Lett., 36, L09821, doi:10.1029/2009GL037464.

Zängl, G., and P. K. Hoinka, 2001: The tropopause in the polar regions. J. Climate, 14, 3117-3139.

Zhang, Z., P. Yang, G. Kattawar, J. Riedi, L. C. Labonnote, B. A. Baum, S. Platnick, and H.-L. Huang, 2009: Influence of ice particle model on satellite ice cloud retrieval: Lessons learned from MODIS and POLDER cloud product comparison. Atmos. Chem. Phys., 9, 7115-7129.

_ , S. Platnick, P. Yang, A. K. Heidinger, and J. M. Comstock, 2010: Effects of ice particle size vertical inhomogeneity on the passive remote sensing of ice clouds. J. Geophys. Res., 115, D17203, doi:10.1029/2010JD013835.

Zuidema, P., and Coauthors, 2005: An Arctic springtime mixedphase cloudy boundary layer observed during SHEBA. J. Atmos. Sci., 62, 160-176. 